AMANDA BOZZA

\title{
Associação dos agentes ocupacionais para a saúde auditiva dos agricultores
}

Tese apresentada à Faculdade de Odontologia de Bauru da Universidade de São Paulo para obtenção do título de Doutor em Ciências no Programa de Fonoaudiologia, na área de concentração Processos e Distúrbios da Comunicação

Orientador: $\operatorname{Prof}^{\underline{a}} \operatorname{Dr}^{\underline{a}}$ Mariza Ribeiro Feniman 
Bozza, Amanda

Associação dos agentes ocupacionais para a saúde auditiva dos agricultores / Amanda Bozza. -Bauru, 2020

Tese (doutorado) -- Faculdade de Odontologia de Bauru, Universidade de São Paulo 2020.

Orientador: Prof. Dr. Mariza Ribeiro Feniman

Autorizo, exclusivamente para fins acadêmicos e científicos, a reprodução total ou parcial desta dissertação/tese, por processos fotocopiadores e outros meios eletrônicos.

Assinatura: 
ERRATA 

FOLHA DE APROVAÇÃO 



\section{DEDICATÓRIA}

Dedico este trabalho aos meus pais e a todos, que assim como eles, acreditam e me fazem acreditar que pesquisar, estudar e não desistir é o melhor, e único, caminho para um mundo melhor. 



\section{AGRADECIMENTOS}

Início meus agradecimentos com aqueles que me deram o dom da vida, me ensinaram a amar ao próximo e aos estudos. Mãe e Pai, eu chego até aqui por vocês e para vocês! Obrigada.

Ao meu marido, amigo e conselheiro Stéfano: muito obrigada! Por estar sempre ao meu lado, pela paciência nesse trajeto, pelas mudanças de planos e pela dedicação na realização deste sonho. Eu te amo!

Kaká, obrigada por me ensinar a trilha do conhecimento e incentivar tanto a minha base. Jô, obrigada pelos momentos de descontração e apoio.

Vó Isa, a minha gratidão eterna por seu apoio incondicional! Você nos ensina, todos os dias, como ser forte, resistente e amável!

Aos meus irmãos obrigada pela parceria de uma vida! Aos meus eternos nenis, o agradecimento por serem meu riso fácil e minha vontade de fazer um mundo melhor. Ao Chefe, obrigada por me mostrar que todos os esforços valem a pena e que a gente pode ser melhor a cada dia.

À toda minha família que sempre me apoiou e acreditou nos meus objetivos, muito obrigada. Nesse leque de pessoas especiais, Bianca, minha eterna confidente, amiga e incentivadora: o mundo precisa de pessoas como você. Ana Vera, obrigada por se tornar minha irmã de coração e por confiar no meu trabalho: você é muito especial!

Uma das minhas primeiras inspirações, aquela que me ensinou a ensinar e ensinar com carinho e terá sempre minha gratidão Prof Dra Andrea Cintra Lopes.

Prof Mariza, obrigada por me acolher e abraçar este sonho de pesquisar fora da minha zona de conforto.

Aos membros docentes da Unversidade do Centro Oeste, assim como minhas alunas queridas do grupo de estudo "Saúde Auditiva dos Trabalhadores", obrigada pela parceria e dedicação.

Aos participantes deste estudo, obrigada pela ajuda, pela hospedagem nas coletas de campo e pelo carinho à mim dedicados. Essa vivência foi o combustível para prosseguir esta pesquisa.

Findo agradecendo à Faculdade de Odontologia de Bauru, por todo suporte dado em tantos anos de formação.

Meus mais sinceros agradecimentos a tudo e a todos que me trouxeram até aqui! 

"Eu sou um intelectual que não tem medo de ser amoroso. Amo as gentes e amo o mundo. E é porque amo as pessoas e amo o mundo que eu brigo para que a justiça social se implante antes da caridade." 



\section{RESUMO}

Um dos fatores mais agravante à saúde auditiva do trabalhador é o ruído. Reconhecido legalmente como otoagressor, está presente em diversos ambientes de trabalho ofuscando outros agentes que também influenciam negativamente na saúde dos trabalhadores. Entre estes agentes, estão os agrotóxicos e os próprios ototóxicos naturais presentes em culturas específicas como a fumicultura, que é conhecida por reter os produtos nela aplicada em todas as fases de plantio e colheita, além de se vincular a substâncias já comprovadamente prejudiciais à saúde auditiva. Com o aumento da preocupação voltada a saúde do trabalhador torna-se imprescindível que pesquisas inovadoras sejam realizadas afim de solidificar e embasar normas regulamentadoras com intuito de garantia de saúde e qualidade de vida aos trabalhadores. Neste caso, em especial a saúde auditiva. Diante disto, o objetivo deste estudo foi investigar e comparar as condições de saúde auditiva e ambiente de trabalho de agricultores de diferentes lavouras, fumicultores e trabalhadores não expostos a agrotóxico. Foram divididos três grupos de trabalhadores, sendo GF com agricultores que trabalham com fumo, GA com agricultores de culturas diversas e GE trabalhadores sem exposição à otoagressores. A metodologia foi dividida em duas etapas: avaliação clínica e avaliação ambiental. $\mathrm{Na}$ avaliação clínica os procedimentos foram entrevista específica, audiometria tonal liminar convencional (ATL), logoaudiometria, medidas de imitância acústica, pesquisa das emissões otoacústicas evocadas transientes (EOA-t) e potencial auditivo de longa latência (P300). A avaliação ambiental contemplou a entrevista específica, medição do nível pressão sonora no ambiente de trabalho dos participantes e levantamento dos insumos agrícolas usados nas diferentes culturas. Essa bateria de testes garantiu a investigação de conhecimento relacionado ao ambiente ocupacional e condições auditiva em nível periférico e central. Os resultados evidenciaram que o GE apresentou maior exposição as intensidades sonoras;; foram identificados 12 agrotóxicos, destes 8 são classificados como altamente ou extremamente tóxicos. Os grupos GA e GF apresentaram limiares piores que o GE. As EOA-t demonstraram que o grupo que apresenta maior funcionalidade de células ciliadas é GE seguido de GA e GF. No P 300, GA e GF apresentaram maior dificuldade para realização do teste, assim como latências aumentadas. 

ABSTRACT

\section{Association of occupational agents for farmers' hearing heal}

One of the most aggravating factors to the worker's hearing health is noise. Legally recognized as an otoagressor, it is present in several work environments, obfuscating other agents that also negatively influence the health of workers. Among these agents, there are pesticides and the natural ototoxic substances present in specific cultures such as tobacco growing, which is known to retain the products applied to it in all planting and harvesting phases, in addition to binding to substances already proven harmful to hearing health. . With the increase in concern for workers' health, it is essential that innovative researches are carried out in order to solidify and support regulatory standards in order to guarantee health and quality of life for workers. In this case, especially hearing health. In view of this, the objective of this study was to investigate and compare the hearing health and working environment conditions of farmers from different crops, tobacco growers and workers not exposed to pesticides. Three groups of workers were divided, GF with farmers who work with tobacco, GA with farmers of different cultures and GE workers without exposure to otoagressors. The methodology was divided into two stages: clinical assessment and environmental assessment. In the clinical evaluation, the procedures were specific interview, conventional pure tone audiometry (ATL), logoaudiometry, acoustic immittance measures, research on transient evoked otoacoustic emissions (EOA-t) and long latency auditory potential (P300). The environmental assessment included the specific interview, measurement of the sound pressure level in the work environment of the participants and survey of the agricultural inputs used in the different cultures. This battery of tests ensured the investigation of knowledge related to the occupational environment and hearing conditions at the peripheral and central levels. The results showed that the SG presented greater exposure to sound intensities; 12 pesticides have been identified, of these 8 are classified as highly or extremely toxic. The GA and GF groups had worse thresholds than the EG. The EOA-t demonstrated that the group that has greater hair cell functionality is GE followed by GA and GF. In the P 300, GA and GF presented greater difficulty to perform the test, as well as increased latencies. Conclusion: The class of farmers studied was not aware of side effects and the correct way of handling pesticides. The type of cultivation may interfere with the action of ototoxic agents in the worker's health, the SPL was not associated with the worst audiological findings and for this evaluation, the high frequency audiometry 
together with the P300 research seems to be effective for the early detection of occupational pathologies. There is an urgent need to implement preventive measures for this population.

Keywords: Hearing, tobacco growers, otoagressors, pesticides, hearing loss, occupational 


\section{LISTA DE ILUSTRAÇÕES}

\section{FIGURAS}

Figura 1 - Vias de contaminação 27

Figura 2 - Uso e manuseio correto de EPI's 76

\section{GRÁFICOS}

Gráfico 1 - Porcentagem dos trabalhadores e sua carga horária diária de $\quad 60$ trabalho

Gráfico 2 - Percepção de Ruído no Ambiente de Trabalho 61

Gráfico 3 - Queixas associadas ao uso de agrotóxicos. 62

Gráfico 4 - $\quad$ Média dos limiares da orelha direita....................................... 66

Gráfico 5 - Média dos limiares da orelha esquerda 66

Gráfico 6 - Média dos resultados de EOAt, por frequência, na OD........... 69

Gráfico 7 Média dos resultados de EOAt, por frequência, na OE............ 69

\section{QUADROS}

Quadro 1 - Classe de toxicidade dos agrotóxicos 29

Quadro 2 - Limite de Tolerância Máxima de Exposição ao ruído. 45

Quadro 3 - Distribuição dos agrotóxicos mencionados 65

Quadro 4 - Porcentagem de acertos por orelha ...................................... 68

\section{LISTA DE TABELAS}

Tabela 1 - Distribuição de gênero e média etária dos grupos 59

Tabela 2 Levantamento de EPI's 62

Tabela 3 - Picos de NPS por hora trabalhada 63

Tabela 4 - $\quad$ Limiares mínimos e máximos da OD, de GE, GA e GF; valor de 67 p para cada frequência

Tabela 5 - Limiares mínimos e máximos da OE, de GE, GA e GF; valor de 67 p para cada frequência

Tabela 6 - Latências registradas no potencial 300 

SUMÁRIO

\begin{tabular}{|c|c|c|}
\hline 1 & INTRODUÇÃO & 21 \\
\hline 2 & FUNDAMENTAÇÃO TEÓRICA & 25 \\
\hline 2.1 & EFEITOS DOS PRODUTOS QUIIMICOS NA SAÚDE GERAL & 25 \\
\hline 2.2 & CONTAMINAÇÃO / INTOXICAÇÃO & 26 \\
\hline 2.3 & CLASSIFICAÇÃO DOS AGROTÓXICOS & 29 \\
\hline 2.4 & AGROTÓXICOS E OTOTOXICIDADE & 30 \\
\hline 2.5 & INTENSIDADE SONORA ELEVADA x PERDA AUDITIVA & 33 \\
\hline 2.6 & AÇÃO DOS PRODUTOS QUÍMICOS X CONDIÇÕES AUDITIVAS & 35 \\
\hline 2.7 & $\begin{array}{l}\text { EFEITOS DA EXPOSIÇÃO SIMULTÂNEA DO RUIIDO E } \\
\text { AGENTES QUÍMICOS A SAÚDE AUDITIVA }\end{array}$ & 38 \\
\hline 2.8 & $\begin{array}{l}\text { TESTES INDICADOS PARA AVALIAÇÃO DO SISTEMA } \\
\text { AUDITIVO DE TRABALHADORES EXPOSTOS Â } \\
\text { OTOAGRESSORES }\end{array}$ & 40 \\
\hline 2.9 & NORMAS REGULAMENTADORAS & 42 \\
\hline 3 & PROPOSIÇÂO & 41 \\
\hline 4 & MATERIAL E MÉTODOS & 43 \\
\hline 4.1 & SELEÇÃO DOS PARTICIPANTES & 43 \\
\hline 4.2 & PROCEDIMENTOS & 43 \\
\hline 4.2 .1 & ENTREVISTA & 43 \\
\hline 4.2 .2 & 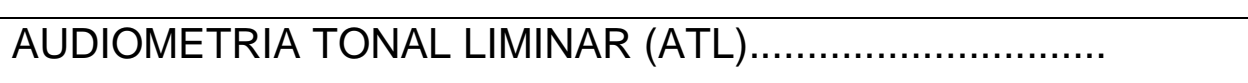 & 43 \\
\hline 4.2 .3 & LOGOAUDIOMETRIA & 44 \\
\hline 4.2 .4 & MEDIDAS DE IMITÂNCIA ACÚSTICA & 44 \\
\hline 4.2 .5 & $\begin{array}{l}\text { EMISSÕES OTOACÚSTICAS EVOCADAS POR ESTÍMULOS } \\
\text { TRANSIENTES (EOA-t): }\end{array}$ & 44 \\
\hline 4.2 .6 & P300 & 45 \\
\hline 4.2 .7 & AVALIAÇÃO AMBIENTAL & \\
\hline 4.3 & ANÁLISE DOS RESULTADOS & 57 \\
\hline 5 & RESULTADOS & 59 \\
\hline 6 & DISCUSSÃO & 73 \\
\hline 7 & CONCLUSÕES & 87 \\
\hline 8 & REFERÊNCIAS & 89 \\
\hline 9 & ANEXOS & 91 \\
\hline
\end{tabular}






\section{INTRODUÇÃO}

Sabe-se que a agricultura no Brasil ocupa um lugar significativo do ponto de vista socioeconômico. O país tem em suas regiões particularidades que fazem com que cada área seja responsável por um tipo de cultivo. A região sul, tem sua maior produtividade voltada à plantação de soja, seguida de milho, trigo, arroz, fumo e batata. Esses cultivos sustentam a economia deste polo, e ainda que o fumo apareça entre os últimos colocados nesta lista, essa região lidera a classificação dos fumicultores brasileiros empregando aproximadamente 144.320 famílias.

Tanta importância socioeconômica deveria ser acompanhada de altos investimentos na saúde dos trabalhadores, visto que o trabalho rural os deixa em riscos diariamente. No entanto, há pouco investimento voltados a este setor o que pode ser justificado pelo difícil acesso aos locais de cultivo e a baixa escolaridade associada à desinformação.

A Legislação ambiental brasileira é considerada uma das mais completas de todo o mundo, no entanto, não garante o compromisso com seu dever em relação a questões sociais e ambientais para chegar mais próximo a sustentabilidade do meio agrícola. Sendo que as únicas medidas/políticas que foram desenvolvidas em relação a poluição excessiva do ambiente (água, ar, terra) e áreas de preservação. (JUDAI \& ANTUNES, 2013).

A preocupação com a saúde da população agrícola se dá pelo contato constante a insumos e a sua manipulação que pode interferir negativamente na qualidade de vida das pessoas. Houveram relatos de que ainda que o contato não seja em grandes proporções já é suficiente para causar prejuízos à saúde em geral como náuseas, dores de cabeça, desconforto estomacais, vômitos e tonturas. Quando o trabalhador fica exposto a esses agentes químicos nocivos à saúde geral pode haver ainda um dano na audição, dessa forma, a perda auditiva pode ser um indício de intoxicação precoce. (SENA et al., 2013). De acordo com a literatura, a incidência de perdas auditivas ocupacionais tem aumentado significantemente. $\mathrm{Na}$ atualidade sabe-se que o ruído não é apenas o único causador dessas perdas auditivas, e que também deve-se levar em consideração os agentes químicos, como por exemplo os agrotóxicos, que são encontrados no ambiente de trabalho da maioria dos agricultores devido à larga escala de produção e industrialização do 
meio agrícola. Esses agentes podem ser mais agressivos de acordo com as culturas. O fumo, por exemplo, apresenta em sua composição natural o tabaco que sozinho já capaz de influenciar negativamente a via auditiva.

Para minimizar os efeitos nocivos à saúde provocados pelos agrotóxicos, algumas medidas preventivas deveriam ser adotadas de acordo com Korbes (2009), em relação a um local adequado para que o trabalhador exposto aos agrotóxicos pudesse guardar e lavar suas roupas de trabalho, realizar sua alimentação e receber orientações com um profissional no assunto em relação a hábitos como passar a mão nas cavidades do rosto, como boca, nariz e olhos, ou seja, cuidado com a saúde do trabalhador. Já de acordo com Manjabosco et al. (2004), as principais medidas de prevenção seria lavagem das mãos, troca de roupa e banho. Porém geralmente essas medidas preventivas não são empregadas deixando na maioria das vezes esses trabalhadores vulneráveis a intoxicações em seus ambientes de trabalho.

Grande parte dos agricultores são expostos aos agrotóxicos no cultivo de suas lavouras e por desconhecerem a relação entre estes produtos e prejuízos auditivos não há uso efetivo de equipamentos de proteção individual (EPI). Este dado revela a importância de estudos que consigam elencar e discutir a presença de agentes agressores ao sistema auditivo em meio laboral, e ainda qualificar a função auditiva destes trabalhadores.

De acordo com Kós et al. (2013), as intoxicações ocupacionais e ambientais muitas vezes são lentas e silenciosas, sendo que o trabalhador pode não sentir dificuldades auditivas que sejam visíveis em um audiograma, no entanto no dia a dia perdem a qualidade sonora da compreensão da fala, interferindo na comunicação.

São inúmeros os casos de intoxicação por agrotóxicos, de acordo com o Relatório Nacional de Vigilância em Saúde de Populações Expostas a Agrotóxicos (2017), foram notificados 79.880 casos de intoxicações no Sinan (Sistema de Informações de Agravos de Notificação) no período entre 2016 e 2017, a situação é ainda mais agravante quando sabe-se que a subnotificação é muito expressiva no Brasil, principalmente em casos de intoxicação crônica, o que acaba dificultando o dimensionamento do problema no país. 
E embora as atividades agrícolas essenciais para a economia brasileira, são escassos os investimentos em envolvem a saúde e segurança nesse setor. $O$ interesse maior é no desenvolvimento de tecnologias para aumento da produtividade e na grande maioria das vezes os impactos a saúde e segurança principalmente do trabalhador não são levados em consideração. 


\section{FUNDAMENTAÇÃO TEÓRICA}

Para facilitar a compreensão do leitor, este capítulo está dividido subtítulos

\subsection{EFEITOS DOS PRODUTOS QUÍMICOS NA SAÚDE GERAL}

Segundo o Ministério da Saúde, em 2002 encontravam-se mais de 750.000 substâncias químicas cadastradas e aproximadamente 85.000 já eram disponibilizadas comercialmente, porém devido ao grande desenvolvimento tecnológico nos últimos anos há uma produção de 1000 a 2000 novos agentes químicos que são disponibilizados para os comércios anualmente.

Em 2018 a Organização Pan Americana de Saúde publicou que a exposição, do ser humano, a várias substâncias químicas ocorre todos os dias meio de muitas vias, como ingestão, inalação, contato com a pele e cordão umbilical do nascituro. Muitas substâncias químicas são inofensivas ou até benéficas; outras são uma ameaça à nossa saúde e ao ambiente. A produção de substâncias químicas continua a crescer e, com ela, o potencial de exposição a tais substâncias.

A lista de substâncias químicas classificadas como carcinógenos humanos que contam com evidências suficientes ou limitadas é longa. Estima-se que os carcinógenos ocupacionais causem entre $2 \%$ e $8 \%$ de todos os cânceres. $\mathrm{Na}$ população em geral, estima-se que 14\% dos cânceres de pulmão sejam atribuíveis à poluição do ar ambiental, 17\% à poluição do ar doméstico, 2\% ao tabagismo passivo e 7\% aos carcinógenos ocupacionais. Há suposições, ainda, de muitas associações entre exposições ambientais e câncer na infância, tais como radiação ionizante e câncer do cérebro, agrotóxicos e leucemia ou benzeno e leucemia ou linfoma. (IARC. WORLD CANCER REPORT 2014). No que se refere a exposição no início da vida, Grandjean e Landrigan (2014) ressaltaram que exposições a produtos químicos no início da vida, como a certos solventes ou agrotóxicos, podem posteriormente induzir à doença de Parkinson.

Substâncias químicas como metais pesados, agrotóxicos, solventes, tintas, detergentes, querosene, monóxido de carbono e fármacos provocam intoxicações não intencionais em casa e no local de trabalho. Estima-se que a intoxicação não intencional provoque 193.000 mortes por ano, sendo a maior parte por exposição 
evitável a substâncias químicas. O risco e o perigo que estão relacionados com as substâncias químicas devem ser trabalhados nas suas várias dimensões, entre as quais destacamos: o potencial de dano do produto, as condições ambientais e do trabalho em que as atividades se desenvolvem e o histórico conhecido daquela realidade e de outras semelhantes a partir dos dados epidemiológicos produzidos e do conhecimento científico existente. (Bozza; Lopes, 2016).

Segundo o manual de biossegurança disponibilizado no site www.fiocruz.br, da Instituição Oswaldo Cruz desde 2018, as intoxicações e/ou envenenamentos por substâncias químicas, incluindo agrotóxicos, apresentam sinais e sintomas como: Dor, sensação de queimação na boca, garganta ou estomago, sonolência, confusão mental, torpor ou outras alterações de consciência, náuseas e vômitos, diarreia, lesões cutâneas, queimaduras intensas com limites bem definidos ou bolhas, convulsões, queda de temperatura, que se mantém abaixo do normal e paralisia.

Todos os trabalhos aqui citados ressaltam ainda que os prejuízos causados pelos produtos químicos podem ser reduzidos ou minimizados com o controle ao acesso dos mesmos.

\subsection{CONTAMINAÇÃO / INTOXICAÇÃO}

De acordo com Moreira et al. (2002), há três maneiras de contaminação por agrotóxico: ambiental, ocupacional e alimentar. A via ambiental refere-se a contaminação por produtos químicos pelos diversos componentes do meio ambiente, já a via ocupacional se caracteriza pelas contaminações nos ambientes de trabalho a partir da manipulação dos produtos químicos. $\mathrm{E}$ a terceira e última via é a alimentar que ocorre através da ingestão de alimentos contaminados pelos agrotóxicos.

Segundo Kós et al. (2013), há três tipos de intoxicações; as agudas, subagudas e crônicas. As intoxicações agudas (são intoxicações nas quais o sintoma surge rapidamente, algumas horas após a exposição ao agrotóxico), ocorrem em uma proporção de aproximadamente 3 milhões ao ano, sendo que 2,1 milhões dos casos são em países que estão se desenvolvendo. $O$ número de óbitos é de aproximadamente 20 mil em todo mundo, porém especialistas acreditam que 
esse número seja maior, pois em muitos lugares ainda não há documentação e registros das intoxicações subagudas (exposição leve ou moderada, sendo que os efeitos podem aparecer em dias ou semanas), há também as intoxicações crônicas que causam danos à saúde mais tardiamente, devido à exposição de meses ou anos aos produtos. As intoxicações podem ocorrer tanto de forma aguda como crônicas, e na maioria dos casos a absorção ocorre pela pele ou por vias respiratórias. E apesar das subnotificações, as intoxicações por agrotóxicos ainda apresentam dentre os casos registrados o $7^{\circ}$ maior percentual e a maioria dos casos são de exposição ocupacional (VANZELLA, 2018).

Consideram-se agentes de risco químico as substâncias, compostos ou produtos que possam penetrar no organismo do trabalhador principalmente pela via respiratória, nas formas de poeira, fumos, gases, neblinas, nevoas ou vapores, ou pela natureza da atividade, de exposição, possam ter contato ou ser absorvido pelo organismo através da pele ou por ingestão. (COMISSÃO PERMANENTE PPRA UNIVERSIDADE DE ALFENAS, 2017. Portal https://www.unifalmg.edu.br/riscosambientais/riscosquimicos).

PRINCIPAIS VIAS DE CONTAMINAÇÃO

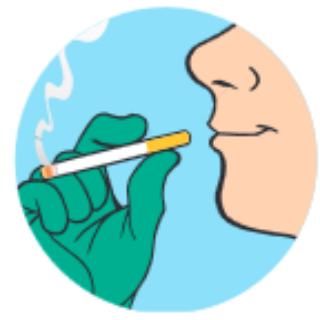

Oral

(boca)

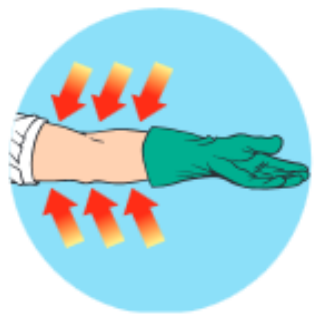

Dérmica

(pele)

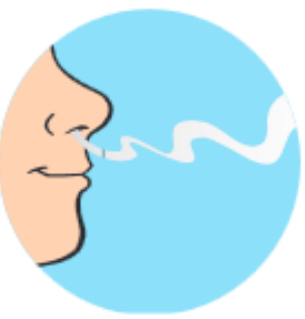

Respiratória

(pulmões)

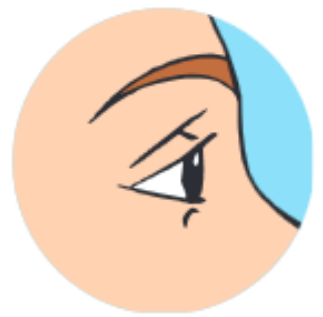

Ocular

(olhos)

https://sites.google.com/site/aplicacaodeprodutosquimicos/principais-vias-de-contaminacao

Figura 1 - Vias de contaminação

Segundo Moreira et al. (2012) os efeitos sistêmicos aparecem rapidamente, em questão de minutos, após a inalação de vapores ou aerossóis. Já após absorção gastrointestinal ou cutânea o aparecimento dos sintomas é tardio. A duração dos 
sinais e sintomas é determinada pelas propriedades do composto principalmente. Os efeitos oculares e respiratórios costumam ser os primeiros a aparecer após exposição local a vapores, aerossóis ou após inalação

Os trabalhadores rurais estão em contato significativo com este tipo de produto o que torna fundamental a compreensão desta exposição: Há dois tipos de contato o direto e o indireto, o primeiro se caracteriza por maior exposição aos agrotóxicos, como por exemplo, os aplicadores, preparadores de calda (pessoa que prepara o veneno), e os responsáveis por depósitos. Já o contato indireto é realizado por meio de roçadas, capinas, colheitas, entre outras práticas rurais. Esses trabalhadores agrícolas estão mais propensos ao risco de contaminação, devido ao constante manejo na lavoura e ao não uso de equipamentos de proteção individual (EPIs).

De acordo com a Organização Mundial de Saúde (1996) no Manual de Populações Expostas a Agrotóxicos estima-se, que aproximadamente, três milhões de pessoas sofrem intoxicação por agrotóxicos no mundo, acarretando 22 mil mortes, a maioria em países em desenvolvimento. (FRANÇA, 2013).

No ano de 2006 o Ministério da Saúde, por meio do Sistema Nacional de Informações Tóxico-Farmacológicas (SINITOX), identificou 76.115 intoxicações, sendo que 200 dos registros foram referentes a óbitos, o maior número de letalidade foi em relação a exposição aos agrotóxicos usados por trabalhadores agrícolas. (SINITOX, 2007). Neste mesmo ano foi identificado 3.289 casos de intoxicação humana por agrotóxicos em todo o país.

No Paraná no ano de 2009 o SINITOX identificou 293 casos de intoxicação por agrotóxicos agrícola, estima-se que 67 foram referentes a acidentes individuais e seis coletivos, 64 casos com origem ocupacional, 151 tentativas de suicídio e um caso de intoxicação por ingestão de alimentos contaminados. A intoxicação ocorreu em ambos os sexos, porém no sexo masculino é mais frequente em uma relação de 207 homens afetados para 86 mulheres. O maior número de casos ocorreu na faixa etária de 20 a 29 anos de idade. Com um total de 15 óbitos por intoxicação apenas neste estado. (FRANÇA, 2013). 


\subsection{CLASSIFICAÇÃO DOS AGROTÓXICOS}

Os agentes químicos são utilizados em grande escala no Brasil, principalmente na agricultura para fins econômicos. Segundo a Agência Nacional de Vigilância Sanitária (Anvisa), órgão responsável por fiscalizar, controlar, regular e normalizar a vigilância sanitária do Brasil, os produtos químicos são classificados de acordo com a toxidade, encontrados no quadro abaixo Quadro 1. Entretanto essa classificação está mais ligada a intoxicação aguda, não indicando, por exemplo, doenças crônicas como o câncer, doenças respiratórias, neuropatias entre outras que se manifestam mais tardiamente. (SENA et al., 2013).

\begin{tabular}{|c|c|c|}
\hline Classes & Toxicidade & Cor \\
\hline Classe I & $\begin{array}{c}\text { Extremamente } \\
\text { Tóxico }\end{array}$ & Vermelho \\
\hline Classe II & Altamente Tóxico & Amarelo \\
Classe III & Moderadamente & Azul \\
\hline Classe IV & Tóxico \\
\hline
\end{tabular}

Quadro 1: Classe de toxicidade dos agrotóxicos

No Brasil há uma grande diversidade de produtos químicos, estima-se que nos agrotóxicos tem-se 300 princípios ativos em 2 mil formulações comerciais diferentes, dessa forma é importante conhecer a sua classificação, ação, e grupo químico a que pertencem, também para o diagnóstico das intoxicações. (SENA et al., 2013).

Essa classificação está descrita de acordo com o Ministério da Saúde (1997) e abrange: 
- Inseticidas (Organofosforados, Carbonatos, Organoclorados e Piretróides);

- Fungicidas (Duter, Brestan, Maneb, Mancozeb, Dithane, Zineb,Tiram,Ortocide, Merpan, Hexaclorobenzeno);

- Herbicidas (Gramoxone, glifosato: Round-up, pentacloofenol, derivados do ácido fenoxiacético: 2,4 diclorofenoxiacético (2,4 D) a 2,4,5 triclorofenoxiacético (2,4,5 T), dinitrofenóis: Dinoseb a DNOC).

A classificação dos agrotóxicos ocorre por meio da toxidade do produto. Sendo o Ministério da Saúde o órgão responsável por determinar essa classificação toxicológica no Brasil.

\subsection{AGROTÓXICOS E OTOTOXICIDADE}

O avanço do consumo de agrotóxicos anualmente, influenciou para as que medidas desenvolvidas em relação à qualidade do meio ambiente não fossem satisfatórias, ou seja, prejudicando-o. No ano de 2009 o Brasil ficou no primeiro lugar no ranking mundial de consumo de agrotóxicos, ainda que não seja o principal produtor agrícola mundial (Carneiro et al, 2015). Em 2019 o número liberado de agrotóxicos aumentou para 382, acrescendo 57 itens da última atualização, segundo nota oficial do Ministério da Agricultura.

De acordo com Körbes (2009) o uso desenfreado dos agrotóxicos está relacionado a vários fatores interligados, entre eles estão: alta toxicidade e o uso inadequado, falta de equipamentos de proteção individual (EPI), e falta de vigilância, assim como o baixo nível socioeconômico da maioria dos trabalhadores. Segundo Garcia (1996) o risco no trabalho com agrotóxicos está ligado necessariamente ao seu manuseio e à sua aplicação. A descontaminação das roupas impregnadas por esses produtos químicos é muito difícil, permanecendo o acúmulo da substância. Dessa forma a pele fica em contato direto como os agentes, provocando a absorção dérmica.

Conforme Körbes (2009) nas condições agrícolas primitivas, haviam poucos problemas nos cultivos em relação aos insetos. Com o passar dos anos a industrialização e a intensificação da agricultura contribuíram para o aumento do 
número de insetos, o plantio apenas de uma cultura em uma vasta extensão de hectares é fato determinante para surgirem insetos específicos, diferentemente quando a cultura é diversificada. Consequentemente com a larga utilização dos agrotóxicos os insetos desenvolvem resistência a seus compostos químicos, ainda mais quando os mesmos pesticidas são utilizados repetidas vezes. Dessa forma para combater essas pragas que se tornam resistentes, os agricultores tendem a aumentar a dosagem dos produtos e suas variedades, tornando-se ainda mais prejudicial em função da contaminação, e uma questão mais grave a saúde pública. De acordo com Meyer et al., (2003), aproximadamente 2,5 a 3 milhões de toneladas de agrotóxicos são utilizados na agricultura anualmente, com a finalidade de acabar com patógenos que ataquem as culturas.

Segundo Hoshino et al., (2008), os trabalhadores tem percepção dos riscos de seu trabalho a saúde e meio ambiente, o que implica na necessidade de mais ações com orientações para a população acerca do uso adequado dos agrotóxicos, assim como uma divulgação de outras formas de plantio que não necessitem de produtos químicos.

De acordo com a literatura a ototoxidade pode ser compreendida como uma ação tóxica que ocorre através de uma reação sobre o sistema auditivo ou vestibular, as seguintes reações podem ser causadas por vários elementos, causando alterações nas estruturas sensoriais da cóclea e estrutura neural, em consequência podem causar perdas auditivas. (JERGER E JERGER, 1998).

Existem alguns produtos químicos e medicamentos que podem acarretar problemas funcionais e a degeneração dos tecidos celulares da orelha interna, como as células ciliadas, órgãos sensoriais e aparelho vestibular. Por esta razão são conhecidas como drogas ototóxicas. Essas drogas ototóxicas podem causar surdez súbita bilateral (temporária ou permanente) ou progressiva. O número dessas drogas é enorme, sendo que o setor agrícola se destaca nessa dimensão devido a questões econômicas e ao crescimento industrial. (BERTONCELLO, 1999).

Diversos estudos têm comprovado que a exposição a agentes otoagressores no ambiente laboral podem trazer consigo problemas auditivos e extra-auditivos. Há um foco voltado a perda auditiva, mas vale considerar que o trabalhador nestas condições pode apresentar alterações no sistema neurológico, circulatório, 
endócrino, imunológico e psíquico. (LUDERS, 2019). Almeida et al., 2012 lembrou que ambientes de trabalho que apresentem desconforto térmico e/ou acústico, muitas horas trabalhadas ininterruptas; esforço físico, postural e sensorial pode ser considerado fatores estressores. Junto com estes fatores estressores temos a perda auditiva que, por sua vez, pode trazer consequências devastadoras para um indivíduo já que afeta diretamente o processo de comunicação e socialização. (GONÇALVES, 2019).

De acordo com Azevedo (2004) a perda auditiva ocupacional por ototoxicidade geralmente se apresenta por ser coclear, simétrica, bilateral e irreversível, sendo que se iniciam nas frequências altas no audiograma. Essas características são muito semelhantes à PAINPSE (Perda Auditiva Induzida por Níveis de Pressão Sonora Elevada), o que pode ser uma possível justificativa para o tema não ter sido pesquisado com sua real importância durante muitos anos, sendo que quando o trabalhador se encontra em um ambiente de trabalho ruidoso e há perdas auditivas a causalidade é atribuída exclusivamente ao ruído, não considerando os efeitos dos agentes químicos que possam influenciar nesse ambiente para a perda auditiva. Em um ambiente com elevados níveis de pressão sonora, não necessariamente, os trabalhadores poderão apresentar os limiares auditivos mais rebaixados quando comparados com trabalhadores expostos à agentes químicos com menor intensidade sonora. Gonçalves, (2019) reitera que a perda auditiva ocupacional é aquela causada pela exposição ao ruído intenso, por produtos químicos ototóxicos ou por qualquer outro agente otoagressivo e que em todos estes casos a PAO é passível de prevenção.

Dentre estes produtos com teor ototóxico temos os insumos agrícolas, que apesar de fundamentais para o cultivo podem trazer malefícios para aqueles que os manipulam, principalmente se não há ciência da prevenção dos males possíveis. No estudo de Rosário et al., 2017, verificou-se que as capacitações em saúde auditiva são necessárias, tanto na Estratégia Saúde da Família como em outros setores envolvidos com educação e saúde. As orientações voltadas ao conhecimento de detecção e prevenção de alterações auditivas são fundamentais na formação continuada dos profissionais envolvidos diretamente com a população, tais como os Agentes Comunitários de Saúde. 
Diante disso, há necessidade de realizar um trabalho para conscientizar os trabalhadores que estão expostos aos agrotóxicos sobre medidas de proteção individual, manejo com as roupas, higiene das mãos, dosagem dos produtos, entre outros aspectos que devem ser esclarecidos aos mesmos com o intuito de minimizar as intoxicações por produtos químicos.

A perda auditiva em que o nexo causal está no ambiente de trabalho é diagnosticada com diversas nomenclaturas como Perda Auditiva Induzida por Ruído (PAIR), Perda Auditiva Ocupacional (PAO), Perda Auditiva Induzida por Níveis de Pressão Sonora Elevada (PAINPSE) e Perda Auditiva Relacionada ao Trabalho (PART), neste estudo a última nomenclatura foi adotada pelo fato de não restringir a perda auditiva ao ruído.

Segundo a Norma Regulamentadora ํㅜ, de 1978, com atualização em 2020, são considerados sugestivos de perda auditiva induzida por níveis de pressão sonora elevados os casos cujos audiogramas, nas frequências de 3.000 e/ou 4.000 e/ou $6.000 \mathrm{~Hz}$, apresentam limiares auditivos acima de $25 \mathrm{~dB}$ (NA) e mais elevados do que nas outras frequências testadas, estando estas comprometidas ou não, tanto no teste da via aérea quanto da via óssea, em um ou em ambos os lados. Tem configuração do tipo sensorineural, sendo na maioria das vezes bilateral, essa perda progride com o tempo de exposição ao ruído e é irreversível.

Fernandes e Lopes (2019) alertaram que quando um trabalhador está exposto a níveis de intensidade sonoras elevadas durante sua jornada de trabalho ele está suscetível a desenvolver alterações auditivas como perda auditiva induzida por níveis de pressão sonora elevada, trauma acústico, mudança temporária de limiar auditivo ou zumbido.

De acordo com Souza et al., (2006), quando o trabalhador é exposto continuamente a um ruído intenso, em média $85 \mathrm{~dB}$ oito horas por dia, ocorrem alterações estruturais na orelha interna, originando a PART. Paraguay (1999) nos 
diz que a perda se inicia nas frequências de $6 \mathrm{kHz}, 4 \mathrm{kHz}$ e/ou $3 \mathrm{kHz}$, evoluindo vagarosamente às frequências $8 \mathrm{kHz}, 2 \mathrm{kHz}, 1 \mathrm{KHz}, 0,5 \mathrm{kHz}$ e 0,25kHz e Ribeiro et al. (2009), complementou que a PAIR deriva de lesões das células sensoriais do órgão de Corti, na orelha interna. As células ciliadas do órgão de Corti são frágeis a altas e prolongadas pressões sonoras, assim, com a morte dessas células, o espaço é ocupado/preenchido por formações cicatriciais, gerando uma deficiência irreversível na habilidade auditiva. Bozza e Lopes, 2016, em um estudo com frentistas de postos de combustíveis, expostos a otoagressores, apresentaram média quadritonal (500,1,2 e $4 \mathrm{KHz})$ dentro dos padrões de normalidade, mas já com configuração característica de PART. Alves e Fiorini (2012) consideraram uma das maiores características deste tipo de perda auditiva o fato de apresentarem caráter insidioso em seu surgimento, resultante de exposição continuada por longos anos. Em geral, se estabiliza após quinze anos de exposição a ruído na ausência de outros fatores agravantes. (FONTOURA et al., 2014).

Araújo (2002) considerou dois aspectos fundamentais para o indivíduo apresentar uma Perda Auditiva Induzida por Ruído: as características do ruído e a suscetibilidade individual.

O primeiro aspecto diz respeito às características do ruído que são: intensidade, frequência, natureza do ruído e tempo de exposição. A intensidade acima de 84/90 dB de ruído origina uma lesão coclear irreversível e quanto maior o ruído mais importante vai ser a lesão. A frequência refere-se que qualquer área do espectro sonoro pode gerar problemas cocleares, porém os mais traumatizantes se caracterizam por aqueles compostos por frequências altas. $O$ tempo de exposição é absolutamente proporcional ao tempo em que o indivíduo fica exposto ao ruído, por exemplo, um indivíduo que fica exposto 100 horas a um ruído já se pode encontrar patologia coclear irreversível, dessa forma intervalos para descanso acústico em ambientes apropriados são essenciais na tentativa de recuperação das enzimas das células sensoriais. Entende-se por intervalo de descanso acústico o período de tempo em que o sujeito exposto ao ruído permanece em ambiente cujo nível de pressão sonora não esteja elevado. Já a natureza do ruído diz respeito à distribuição da energia sonora durante o tempo, que pode ser contínua, flutuante e intermitente. (ARAÚJO, 2002). 
Segundo Souza et al., (2006), quando a exposição ao ruído ocorre de forma brusca e intensa, pode desencadear o trauma acústico, com possibilidade de lesionar transitoriamente ou definitivamente estruturas da cóclea. Outra alteração que o ruído desencadeia é a mudança temporária de limiar, redução da acuidade auditiva (podendo voltar ao normal após um período de afastamento do ruído). Os trabalhadores expostos ao ruído intenso além de apresentar perda auditiva, zumbido, dificuldade de compreensão de fala, tem muitas vezes cefaleia, tontura, problemas digestivos, irritabilidade, entre outras queixas.

Em relação à percepção ambiental o indivíduo com PAIR pode apresentar dificuldades em ouvir sons domésticos, alarmes, necessidade de volume elevado para escutar a televisão e rádio, dificuldades em se comunicar com grupos de pessoas, lugares ruidosos, no telefone. O trabalhador com PAIR demanda grande esforço e fadiga, pois tem maior necessidade de atenção e concentração nas tarefas que são necessárias o sentido da audição, sua autoimagem é negativa, pois este trabalhador se acha surdo, velho ou incapaz muitas vezes se isolando do contato com outras pessoas, o que gera depressão, irritabilidade e angústia. (OLMI, 2011).

De acordo com as considerações de Marukami, Pinto, Albuquerque e Lacerda, (2017) o resultado de seu estudo demonstrou que três manifestações mais comuns nas intoxicações crônicas por exposição a múltiplos agrotóxicos encontradas foram: transtornos psiquiátricos menores $(90 \%)$, perda auditiva sensorioneural (15\%) e polineuropatia tardia induzida por organofosforados $(10 \%)$.

Pesquisas voltadas à área de saúde do trabalhador se mantêm estudando condições de saúde auditiva no ambiente de trabalho para reduzir as perdas auditivas relacionadas ao trabalho (PART), que afetam severamente a qualidade de vida do trabalhador.

\subsection{AÇÃO DOS PRODUTOS QUÍMICOS X CONDIÇÕES AUDITIVAS}

Estudos encontrados na literatura evidenciam que as substâncias químicas estão associadas a alterações auditivas, por exemplo no uso de drogas ototóxicas, na exposição à solventes orgânicos e agrotóxicos. Dado importante, pois até então, 
a maioria dos estudos sobre os danos auditivos relacionados à saúde de trabalhadores eram associados quase que unicamente aos riscos de exposição ao ruído. (KÓS et al., 2013).

Ainda de acordo com Kós et al. (2013), em muitos casos a intoxicação ocupacional e ambiental por agrotóxicos ocorre de forma lenta e silenciosa, e os sujeitos podem não sentir alterações auditivas que apareçam em audiogramas, porém há influência em sua qualidade de vida, dificultando a compreensão de fala, e em consequência a comunicação. Esses autores realizaram um levantamento e seleção de 16 trabalhos encontrados na literatura, os demais foram excluídos por alguns aspectos pré-estabelecidos: como por exemplo, a associação da exposição do agrotóxico com ruído, o foco era apenas estudos que os trabalhadores fossem expostos somente aos produtos químicos. Constataram que em todos os 16 trabalhos há relação entre a exposição e alterações auditivas, dessa forma a exposição leva ao dano periférico e/ou central das vias auditivas.

De acordo com Körbes et al, (2010):

"No sistema vestibulococlear, o efeito de agentes ototóxicos pode manifestar-se em lesões de células ciliadas externas (CCE), lesões do VIII par craniano, alterações no sistema vestibular e alterações no sistema nervoso central (SNC). A ação neurotóxica de algumas substâncias químicas encontradas nos ambientes de trabalho pode afetar não somente a audição e o equilíbrio, mas também o tronco cerebral e via auditivas centrais. Há evidências de que a alteração auditiva possa ser uma manifestação precoce de intoxicação por organofosforados".

Ainda em relação com o sistema-vestibulococlear, os produtos químicos ototóxicos podem gerar lesões no VIII par craniano, nas células ciliadas externas (CCE) e alterações no sistema vestibular e no sistema nervoso central (SNC). Ou seja, os efeitos dos agentes químicos podem afetar além da audição e equilíbrio, também as vias auditivas centrais e o tronco cerebral (KÖRBES, 2009).

De acordo com a pesquisa de Körbes (2009), com cobaias submetidas a agrotóxicos os organofosforados têm efeito lesivo para as células ciliadas externas (CCE), sendo fato determinante a relação entre dosagem e as alterações observadas no microscópio. Os danos que ocorrem à cóclea atingem os estereocílios das CCE e evoluem para espira basal. Ainda segundo o autor 
ocorreram alterações morfológicas na cóclea, utrículo e sáculo das cobaias que ficaram expostas aos organosfosfatos, acarretando efeitos degradantes ao sistema vestibulococlear.

Alguns estudos sugerem que o organofosfato (um tipo de pesticida) ou paraquat (um tipo de herbicida) pode promover a formação de espécies reativas de oxigênio (ERO) dentro do espaço perilinfático no cóclea. A formação resultante de ERO pode ser tóxica para a cóclea (BIELEFELD ET AL, 2005; JAYASINGHE \& PATHIRANA, 2011).

Conforme Teixeira et al. (2002), em seu estudo com pulverizadores de veneno contra a dengue, evidenciou que dos $56 \%$ dos trabalhadores expostos apresentaram alterações no processamento auditivo central (PAC), sendo que os resultados indicam que a exposição aos produtos químicos: piretroides e organofosforados comprometem as funções auditivas centrais.

Dessa forma para prevenir a perda auditiva as exposições químicas devem ser controladas e monitoradas. Os trabalhadores que sofrem exposição a esses agentes químicos devem ser incluídos em programas de conservação auditiva, pois esses inseticidas causam danos ao sistema auditivo periférico, com a presença ou não do ruído. (TEIXEIRA et al., 2002).

As lesões no sistema auditivo e vestibular podem acontecer de diversas formas de acordo com o tipo de ototóxico e susceptibilidade individual e condições de intoxicação, entre elas estão: associação com outros químicos e/ou ruídos e concentração do produto, assim como fatores agravantes, como a idade (idoso ou criança) pode ser mais prejudicial. (TEIXEIRA et al., 2002).

Camarinha et al. (2011) realizaram um estudo com 43 trabalhadores agrícolas, para avaliar o processamento auditivo temporal em trabalhadores expostos ocupacionalmente a agrotóxicos organofosforados. Observaram que o desempenho da maior parte dos trabalhadores nos testes de processamento auditivo temporal foi inferior em relação aos padrões de normalidade. As habilidades auditivas de resolução temporal e ordenação temporal mostram-se comprometidas em indivíduos expostos ao organofosforado, mesmo estes apresentando audição periférica normal. 
Romano et al., 2016 investigaram o efeito das funções auditivas centrais em trabalhadores expostos à agrotóxicos e comparou ao seu grupo controle. Os resultados mostraram que produtores de tabaco expostos a pesticidas exibiram sinais de disfunção auditiva central caracterizada por decréscimos no processamento temporal processos / habilidades de integração binaural.

De acordo com os toxicologistas das indústrias, os ototóxicos correspondem a todos os elementos físicos e químicos capazes de lesar à função auditiva. (HOSHINO et al, 2008).

No estudo de Bazílio (2010) realizado com agricultores, os trabalhadores que foram expostos aos agrotóxicos apresentaram estatisticamente resultados piores nos exames de processamento auditivo temporal. Concluíram que estas sustâncias são prejudiciais as vias auditivas centrais.

O produto neurotóxico pode lesar não somente o componente periférico da audição, assim como o componente central. Dessa forma são necessários novos estudos para conhecer melhor os e feitos dos produtos químicos em relação a audição, visando maior segurança, e auxiliando no desenvolvimento de estratégias para prevenção da perda auditiva.

Para Lacerda e Morata (2010), os produtos tóxicos podem gerar prejuízos nas estruturas e funções da orelha interna, sendo que o dano não é necessariamente no ducto coclear. Os mecanismos, o local e a extensão da lesão variam de acordo com os fatores de risco, entre eles estão: tipo de produto ototóxico, associação com outros agentes, duração da exposição, entre outros aspectos. Essas autoras frisam a dificuldade na detecção e no diagnóstico precoce da ação ototóxica desses produtos para a Audiologia.

\subsection{EFEITOS DA EXPOSIÇÃO SIMULTÂNEA DO RUÍDO E AGENTES QUÍMICOS A SAÚDE AUDITIVA}

Sabe-se que o sujeito pode estar em contato com distintos agentes concomitantemente, sejam eles físicos, químicos ou biológicos, em seu ambiente de trabalho ou não. Esses agentes podem interagir de diversas formas. 
De acordo com Azevedo (2004) a exposição simultânea ao ruído e agentes químicos leva a uma perda auditiva, maior do que quando o sujeito é exposto isoladamente:

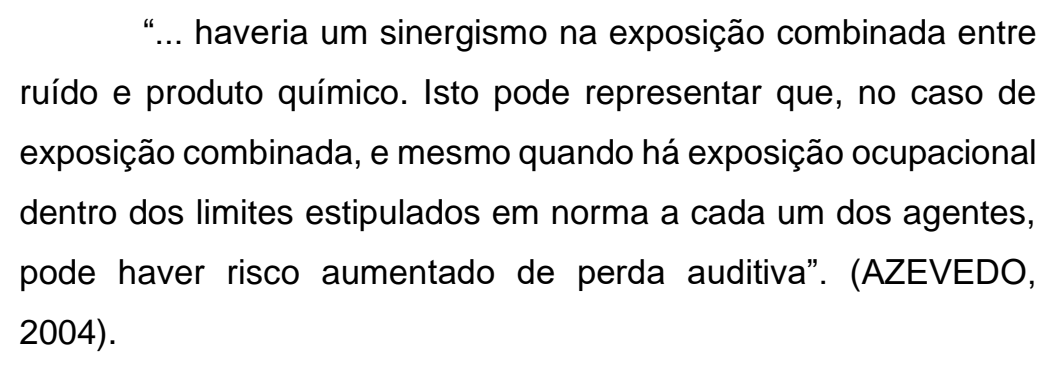

Sendo assim, de acordo com o autor supracitado quando o sujeito sofre exposição conjunta de dois agentes nocivos a audição, no caso o ruído e agente químico a perda de audição tende a ser potencializada.

Outro estudo que evidencia os efeitos da associação do ruído aos agrotóxicos é o de Foltz, Soares e Reichembac (2010), os mesmos encontraram ocorrência de perda auditiva indicativa de perda auditiva induzida pelo ruído em $29,3 \%$ dos pilotos agrícolas analisados. Além da exposição ao ruído os pilotos agrícolas podem sofrer uma intoxicação por agrotóxico, por meio da inalação, dessa forma nesse estudo observaram que há uma tendência estatística na associação entre configuração audiométrica e contato com agrotóxico ( $p=0,088)$. Com o estudo pode-se observar que os pilotos agrícolas apresentam elevado índice de perda auditiva, devido à associação do ruído e agrotóxico.

No estudo de Manjabosco et al., (2004), com trabalhadores rurais, foram identificados no grupo exposto uma porcentagem de $60 \%$, o que equivale a 25 agricultores com limiares de audição alterados. Sendo que 23 apresentaram perda auditiva de origem ocupacional, entre elas $17 \%$ por ruído e $83 \%$ correspondente ao ruído e agrotóxico simultaneamente.

Há evidencias que os produtos químicos podem acarretar problemas tanto ou mais graves que a perda auditiva. Em contraponto, há indicações de que essa perda auditiva poderia ser uma das iniciais manifestações da intoxicação por produtos químicos, podendo ocorrer mesmo com a ausência do ruído. Também deve se atentar ao fato da possibilidade dessa perda auditiva progredir ainda posteriormente ao término da exposição ao agente químico (AZEVEDO, 2004). 
Bozza e Lopes (2016) relataram que trabalhadores de um posto de combustível que não estavam sob exposição sonora, mas sim expostos a agentes químicos da gasolina e etanol apresentaram entalhe característico da PAINPSE. Esta configuração, neste estudo, ainda se relacionou com a prevalência de leucopenia. Prestes (2018) investigou a prevalência dos sintomas osteomusculares e a qualidade de vida no trabalho de frentistas e correlacionou com avaliações audiológicas. Foram verificadas alterações auditivas nos frentistas sugerindo ação tóxica da exposição a combustíveis. Concluíram ainda que os sintomas osteomusculares encontrados nos frentistas possam ser consequências das condições laborais.

$\mathrm{Na}$ literatura são escassas as pesquisas sobre o a ação dos produtos ototóxicos isoladamente para a audição, mas de acordo com os trabalhos encontrados há evidências que os agrotóxicos podem gerar perda auditiva sem a presença do ruído. No entanto, quando em conjunto eles são potencializados, podendo causar agravos a saúde do trabalhador.

\subsection{TESTES INDICADOS PARA AVALIAÇÃO DO SISTEMA AUDITIVO DE TRABALHADORES EXPOSTOS À OTOAGRESSORES}

Já é sabido da interferência do ruído e suas características no perfil audiológico destes trabalhadores, mas com o aumento de estudos apontando a real influência dos agentes químicos no sistema auditivo a necessidade de diagnóstico precoce e assertivo já é uma preocupação. Com isso, este subitem tem a função de explanar quais os testes vêm sendo praticado nesta população de risco.

Sena et al., 2013 já nos alertava quanto à necessidade de novos estudos afim de garantir uma bateria de testes eficaz e avaliação de outros aspectos, além da saúde auditiva, na população agrícola. Em seu estudo puderam comprovar que a exposição ao agrotóxico traz consequências que podem ser apontadas pela audiometria tonal convencional. Também em 2013, FRANÇA, não encontrou diferença nos achados audiológicos entre seus grupos de estudo, fumicultores e grupo controle, apesar de ter sugerido que a exposição a agrotóxicos pode afetar a 
audição nas suas estruturas mais superiores, pertencentes ao Sistema Auditivo Nervoso Central.

Coelho et al., (2010) evidenciaram a importância da utilização das emissões otoacústicas no diagnóstico diferencial da perda auditiva induzida por ruído (PAIR). Concluíram que tanto as emissões otoacústicas transientes (EOAT) quanto às emissões otoacústicas por produto de distorção (EOAPD) são úteis no diagnóstico precoce da PAIR sendo que as EOAT se revelam mais sensíveis às mudanças temporárias de limiar que as EOAPD e as EOAPD se destacam mais eficazes no diagnóstico precoce da PAIR em indivíduos com audição aparentemente normal por captar respostas nas frequências mais agudas que são primeiramente atingidas na PAIR. Em 2013, Alcarás PAS et al estudaram a eficácia da pesquisa de EOA em sujeitos expostos à ruído e agrotóxicos comparando os resultados deste grupo com seu grupo controle. Encontraram diferença entre os achados das EOAET e EOAEPD entre os grupos, GRA e GC. Os participantes do Grupo com exposição apresentaram piores resultados nos achados das EOAE, o que sugere que este teste pode ser usado na identificação precoce dos agravos à audição dos trabalhadores expostos simultaneamente a agrotóxicos e ruído.

Em 2011, Camarinha et al., com o objetivo de avaliar as habilidades de processamento auditivo temporal em trabalhadores expostos a agrotóxicos organofosforados, observaram que as habilidades auditivas de resolução temporal e ordenação temporal mostram-se comprometidas em indivíduos expostos ao organofosforado, mesmo estes apresentando audição periférica normal. França, (2013) também realizou avaliação de processamento auditivo e terminou seu estudo com avaliação audiológica central mostrando não haver diferença estatisticamente significativa, entre o grupo de pesquisa (G1) e o grupo controle (G2) nos resultados da avaliação dos Potenciais Evocados Auditivos de Tronco Encefálico, mas foram encontradas diferenças, estatisticamente significativas, entre os grupos no Teste Dicótico de Dígitos e Radom Gap Detection Teste $(p<0,05)$. Trabanco J (2019), avaliou a influência do agente ruído e do agente químico na audição periférica e nas habilidades de processamento auditivo central e apesar de não encontrar diferença significativa entre estes grupos, encontrou alteração dos achados quando comparados aos padrões de normalidade.

Kamita (2014) analisou os resultados obtidos no exame de P300 de frentistas de postos de gasolina do município de Joinville-SC. Os resultados obtidos na 
amplitude do P300 sugerem a presença de alterações no Sistema Nervoso Auditivo Central, a nível cortical, dos frentistas estudados. No entanto, os resultados obtidos na latência do P300 não foram alterados.

$\mathrm{Na}$ literatura nacional ainda são escassos os trabalhos envolvendo agrotóxicos e pesquisa da onda 300ms (P300), em 2017 na Universidade de Sri Lanka, Dassanayake descreveu a ação de organofosforados como sendo um grande problema clínico e de saúde pública no sul da Ásia, tendo em vista que atuam como inibidores da colinesterase e provocam déficits neurológicos agudos após a exposição. Foi comparado o resultado do p300 entre o grupo exposto a organofosforado, um grupo controle e ainda a um grupo de pacientes com histórico de overdose de paracetamol (este, após recuperação total de caso clínico). Como resultado foi encontrado um aumento significante de latência e ainda um abaulamento na amplitude das ondas no grupo exposto a organofosforado.

Contudo é possível notar que ainda há divergências e escassez dados de quanto a definição da melhor bateria de testes a ser adotada diante de casos de exposição a agentes químicos e/ou agrotóxicos. No entanto, deve-se levar sempre em consideração os achados que comprovam que essa exposição interfere negativamente na via auditiva central e periférica.

Santos et al., 2019 relataram que a exposição a agrotóxicos de uso ocupacional tem determinado intoxicações crônicas identificadas, pelos transtornos psiquiátricos menores e pela polineuropatia tardia. Faz-se necessário reforçar discussão nacional, no que diz respeito a legalização, vigilância e controle dos agentes.

\subsection{NORMAS REGULAMENTADORAS}

As Normas Regulamentadoras (NRs) são portarias do antigo Ministério do Trabalho, alocadas na atual Secretaria de Inspeção do Trabalho do Ministério da Economia. As Normas Regulamentadoras (NR) são disposições complementares ao capítulo V da CLT, consistindo em obrigações, direitos e deveres a serem cumpridos por empregadores e trabalhadores com o objetivo de garantir trabalho seguro e sadio, prevenindo a ocorrência de doenças e acidentes de trabalho. Ou seja, cada ambiente e condição de trabalho tem sua norma com a responsabilidade 
de garantir a segurança e bem-estar do trabalhador. Aqui abordaremos aquelas que cabem na discussão da saúde auditiva dos trabalhadores.

\subsubsection{NR 6 - EQUIPAMENTO DE PROTEÇÃO INDIVIDUAL - EPI}

Esta NR teve sua primeira versão em 1978 e sua última atualização no ano de 2020, ela considera que "Equipamento de Proteção Individual - EPI", todo dispositivo ou produto, de uso individual utilizado pelo trabalhador, destinado à proteção de riscos suscetíveis de ameaçar a segurança e a saúde no trabalho.

\footnotetext{
"Entende-se como Equipamento Conjugado de Proteção Individual, todo aquele composto por vários dispositivos, que o fabricante tenha associado contra um ou mais riscos que possam ocorrer simultaneamente e que sejam suscetíveis de ameaçar a segurança e a saúde no trabalho. O equipamento de proteção individual, de fabricação nacional ou importado, só poderá ser posto à venda ou utilizado com a indicação do Certificado de Aprovação - CA, expedido pelo órgão nacional competente em matéria de segurança e saúde no trabalho do Ministério do Trabalho e Emprego.
}

O empregador é obrigado a fornecer aos empregados, gratuitamente, EPI adequado ao risco, em perfeito estado de conservação e funcionamento, nas seguintes circunstâncias: sempre que as medidas de ordem geral não ofereçam completa proteção contra os riscos de acidentes do trabalho ou de doenças profissionais e do trabalho; enquanto as medidas de proteção coletiva estiverem sendo implantadas; e, para atender a situações de emergência.

No que se refere à proteção auditiva, o item C - EPI PARA PROTEÇÃO AUDITIVA C.1 - Protetor auditivo a) protetor auditivo circum-auricular para proteção do sistema auditivo contra níveis de pressão sonora superiores ao estabelecido na NR-15; b) protetor auditivo de inserção para proteção do sistema auditivo contra níveis de pressão sonora superiores ao estabelecido c) protetor auditivo semiauricular para proteção do sistema auditivo contra níveis de pressão sonora superiores ao estabelecido na NR-15. Esta NR trata das atividades ou operações insalubres as que se desenvolvem, e determina os limites de tolerância previstos nos Anexos. Desta forma, deve usar protetores auriculares aqueles que estiverem submetidos a estes níveis de pressão sonora: 


\begin{tabular}{|c|c|}
\hline $\begin{array}{ll} & \text { NÍVEL } \\
\text { RuÍDo } & \\
& \text { dB (A) }\end{array}$ & $\begin{array}{l}\text { MÁXIMA EXPOSIÇÃO } \\
\text { DIÁRIA } \\
\text { PERMISSÍVEL }\end{array}$ \\
\hline 85 & 8 horas \\
\hline 86 & 7 horas \\
\hline 87 & 6 horas \\
\hline 88 & 5 horas \\
\hline 89 & $\begin{array}{llll}4 & \text { horas } & \text { e } & 30 \\
\text { minutos } & & & \end{array}$ \\
\hline 90 & 4 horas \\
\hline 91 & $\begin{array}{llll}3 & \text { horas } & \text { e } & 30 \\
\text { minutos } & & & \end{array}$ \\
\hline 92 & 3 horas \\
\hline 93 & $\begin{array}{llll}2 & \text { horas } & \text { e } & 40 \\
\text { minutos } & & & \\
\end{array}$ \\
\hline 94 & $\begin{array}{llll}2 & \text { horas } & \text { e } & 15 \\
\text { minutos } & & & \end{array}$ \\
\hline 95 & 2 horas \\
\hline 96 & 1 hora e 45 minutos \\
\hline 98 & 1 hora e 15 minutos \\
\hline 100 & 1 hora \\
\hline 102 & 45 minutos \\
\hline 104 & 35 minutos \\
\hline 105 & 30 minutos \\
\hline 106 & 25 minutos \\
\hline 108 & 20 minutos \\
\hline
\end{tabular}




\begin{tabular}{|c|c|}
\hline 110 & 15 minutos \\
\hline 112 & 10 minutos \\
\hline 114 & 8 minutos \\
\hline 115 & 7 minutos \\
\hline
\end{tabular}

Quadro2: Limite de Tolerância Máxima de Exposição ao ruído.

A NR15 ainda prevê situações de ruído de impacto. Entende-se por ruído de impacto aquele que apresenta picos de energia acústica de duração inferior a 1(um) segundo, a intervalos superiores a 1 (um) segundo. Nestes casos os níveis de impacto deverão ser avaliados em decibel (dB), com medidor de nível de pressão sonora operando no circuito linear e circuito de resposta para impacto. As leituras devem ser feitas próximas a orelha do trabalhador. O limite de tolerância para ruído de impacto será de $130 \mathrm{~dB}$ (linear). Nos intervalos entre os picos, o ruído existente deverá ser avaliado como ruído contínuo.

\subsubsection{NORMA REGULAMENTADORA 7}

A NR7, já citada no item 2.4, elaborada em 1978 e com sua última atualização em 2013 estabelece a obrigatoriedade de elaboração e implementação, por parte de todos os empregadores e instituições que admitam trabalhadores como empregados, do Programa de Controle Médico de Saúde Ocupacional - PCMSO, com o objetivo de promoção e preservação da saúde do conjunto dos seus trabalhadores.

Especificamente à audição tem-se o ANEXO I do QUADRO II (Incluído pela Portaria n. ${ }^{\circ} 19$, de 09 de abril de 1998) nomeado "DIRETRIZES E PARÂMETROS MÍNIMOS PARA AVALIAÇÃO E ACOMPANHAMENTO DA AUDIÇÃO EM TRABALHADORES EXPOSTOS A NÍVEIS DE PRESSÃO SONORA ELEVADOS". Os objetivos são: Estabelecer diretrizes e parâmetros mínimos para a avaliação e o acompanhamento da audição do trabalhador através da realização de exames 
audiológicos de referência e sequenciais; e fornecer subsídios para a adoção de programas que visem a prevenção da perda auditiva induzida por níveis de pressão sonora elevados e a conservação da saúde auditiva dos trabalhadores.

Segundo esta NR entende-se por perda auditiva por níveis de pressão sonora elevados as alterações dos limiares auditivos, do tipo sensorioneural, decorrente da exposição ocupacional sistemática a níveis de pressão sonora elevados. Tem como características principais a irreversibilidade e a progressão gradual com o tempo de exposição ao risco. A sua história natural mostra, inicialmente, o acometimento dos limiares auditivos em uma ou mais frequências da faixa de 3.000 a $6.000 \mathrm{~Hz}$. As frequências mais altas e mais baixas poderão levar mais tempo para serem afetadas. Uma vez cessada a exposição, não haverá progressão da redução auditiva. No quesito exames, entende-se por exames audiológicos de referência e sequenciais o conjunto de procedimentos necessários para avaliação da audição do trabalhador ao longo do tempo de exposição ao risco, incluindo: anamnese clínico-ocupacional; exame otológico; exame audiométrico realizado segundo os termos previstos nesta norma técnica, outros exames audiológicos complementares solicitados a critério médico.

Após dispor sobre as condições de avaliação e dos equipamentos esta NR indica como deve ser realizada a interpretação dos resultados obtidos em diversas situações:

1.1. São considerados dentro dos limites aceitáveis, para efeito desta norma técnica de caráter preventivo, os casos cujos audiogramas mostram limiares auditivos menores ou iguais a $25 \mathrm{~dB}(\mathrm{NA})$, em todas as frequências examinadas.

1.2. São considerados sugestivos de perda auditiva induzida por níveis de pressão sonora elevados os casos cujos audiogramas, nas frequências de 3.000 e/ou 4.000 e/ou $6.000 \mathrm{~Hz}$, apresentam limiares auditivos acima de $25 \mathrm{~dB}(\mathrm{NA})$ e mais elevados do que nas outras frequências testadas, estando estas comprometidas ou não, tanto no teste da via aérea quanto da via óssea, em um ou em ambos os lados. 
1.3. São considerados não sugestivos de perda auditiva induzida por níveis de pressão sonora elevados os casos cujos audiogramas não se enquadram nas descrições contidas nos itens 4.1.1 e 4.1.2 acima.

2. A interpretação dos resultados do exame audiométrico sequencial deve seguir os seguintes parâmetros:

2.1. São considerados sugestivos de desencadeamento de perda auditiva induzida por níveis de pressão sonora elevados, os casos em que os limiares auditivos em todas as frequências testadas no exame audiométrico de referência e no sequencial permanecem menores ou iguais a $25 \mathrm{~dB}(\mathrm{NA})$, mas a comparação do audiograma sequencial com o de referência mostra uma evolução dentro dos moldes definidos nesta norma, e preenche um dos critérios abaixo: a) a diferença entre as médias aritméticas dos limiares auditivos no grupo de frequências de 3.000 , 4.000 e $6.000 \mathrm{~Hz}$ iguala ou ultrapassa $10 \mathrm{~dB}(\mathrm{NA})$; b) a piora em pelo menos uma das frequências de $3.000,4.000$ ou $6.000 \mathrm{~Hz}$ iguala ou ultrapassa $15 \mathrm{~dB}(\mathrm{NA})$.

2.2. São considerados, também sugestivos de desencadeamento de perda auditiva induzida por níveis de pressão sonora elevados, os casos em que apenas o exame audiométrico de referência apresenta limiares auditivos em todas as frequências testadas menores ou iguais a $25 \mathrm{~dB}(\mathrm{NA})$, e a comparação do audiograma sequencial com o de referência mostra uma evolução dentro dos moldes definidos aqui, e preenche um dos critérios abaixo: a) a diferença entre as médias aritméticas dos limiares auditivos no grupo de frequência de 3.000, 4.000 e $6.000 \mathrm{~Hz}$ iguala ou ultrapassa $10 \mathrm{~dB}(\mathrm{NA})$; b) a piora em pelo menos uma das frequências de $3.000,4.000$ ou $6.000 \mathrm{~Hz}$ iguala ou ultrapassa $15 \mathrm{~dB}(\mathrm{NA})$.

2.3. São considerados sugestivos de agravamento da perda auditiva induzida por níveis de pressão sonora elevados, os casos já confirmados em exame audiométrico de referência, e nos quais a comparação de exame audiométrico sequencial com o de referência mostra uma evolução dentro dos moldes definidos nesta norma, e preenche um dos critérios abaixo: a) a diferença entre as médias aritméticas dos limiares auditivos no grupo de frequência de $500,1.000$ e $2.000 \mathrm{~Hz}$, ou no grupo de frequências de $3.000,4.000$ e $6.000 \mathrm{~Hz}$ iguala ou ultrapassa 10 $\mathrm{dB}(\mathrm{NA})$; b) a piora em uma frequência isolada iguala ou ultrapassa $15 \mathrm{~dB}(\mathrm{NA})$. 
2.4. Para fins desta norma técnica, o exame audiométrico de referência permanece o mesmo até o momento em que algum dos exames audiométricos sequenciais for preenchido algum dos critérios apresentados em 4.2.1, 4.2.2 ou 4.2.3. Uma vez preenchido por algum destes critérios, deve-se realizar um novo exame audiométrico, dentro dos moldes previstos nesta norma técnica, que será, a partir de então, o novo exame audiométrico de referência. Os exames anteriores passam a constituir o histórico evolutivo da audição do trabalhador.

O diagnóstico conclusivo, o diagnóstico diferencial e a definição da aptidão para o trabalho, na suspeita de perda auditiva induzida por níveis de pressão sonora elevados, estão a cargo do médico coordenador do PCMSO de cada empresa, ou do médico encarregado pelo mesmo para realizar o exame médico, dentro dos moldes previstos na NR - 7, ou, na ausência destes, do médico que assiste ao trabalhador.

\subsubsection{NORMA REGULAMENTADORA 9}

Esta Norma Regulamentadora - NR, em vigor desde 1978 e com última atualização em 2019, estabelece a obrigatoriedade da elaboração e implementação, por parte de todos os empregadores e instituições que admitam trabalhadores como empregados, do Programa de Prevenção de Riscos Ambientais - PPRA, visando à preservação da saúde e da integridade dos trabalhadores, através da antecipação, reconhecimento, avaliação e consequente controle da ocorrência de riscos ambientais existentes ou que venham a existir no ambiente de trabalho, tendo em consideração a proteção do meio ambiente e dos recursos naturais.

O PPRA é parte integrante do conjunto mais amplo das iniciativas da empresa no campo da preservação da saúde e da integridade dos trabalhadores, devendo estar articulado com o disposto nas demais NR, em especial com o Programa de Controle Médico de Saúde Ocupacional - PCMSO previsto na NR7.

O Programa de Prevenção de Riscos Ambientais deverá conter, no mínimo, a seguinte estrutura: a) planejamento anual com estabelecimento de metas, prioridades e cronograma; b) estratégia e metodologia de ação; c) forma 
do registro, manutenção e divulgação dos dados; d) periodicidade e forma de avaliação do desenvolvimento do PPRA. Dentro destas atividades o objetivo será sempre promover a saúde coletiva dos trabalhadores e se antecipar aos possíveis danos.

\subsubsection{NORMA REGULAMENTADORA- 31}

Em vigor desde 2005 e em constante aprimoramento, último em 2018, a norma regulamentadora $\mathrm{n}^{\circ} 31$ tem por objetivo estabelecer procedimentos e regras seguras que garantam a integridade física dos trabalhadores que atuam nas áreas contempladas nessa norma. A NR31 é aplicada para as atividades de: pecuária, agricultura, silvicultura, aquicultura, exploração florestal e exploração industrial (quando tal atividade é realizada em estabelecimentos agrários).

Num breve resumo, esta NR se destina a garantir que a Secretaria de Inspeção do Trabalho - SIT, através do Departamento de Segurança e Saúde no Trabalho - DSST, defina, coordene, oriente e implemente a política nacional em segurança e saúde no trabalho rural para: a) identificar os principais problemas de segurança e saúde do setor, estabelecendo as prioridades de ação, desenvolvendo os métodos efetivos de controle dos riscos e de melhoria das condições de trabalho; b) avaliar periodicamente os resultados da ação; c) prescrever medidas de prevenção dos riscos no setor observado os avanços tecnológicos, os conhecimentos em matéria de segurança e saúde e os preceitos aqui definidos; d) avaliar permanentemente os impactos das atividades rurais no meio ambiente de trabalho; e) elaborar recomendações técnicas para os empregadores e empregados e para trabalhadores autônomos observados os usos e costumes regionais; (Alterada pela Portaria MTb n.. 1.086, de 18 de dezembro de 2018) f) definir máquinas e equipamentos cujos riscos de operação justifiquem estudos e procedimentos para alteração de suas características de fabricação ou de concepção; g) criar um banco de dados com base nas informações disponíveis sobre acidentes, doenças e meio ambiente de trabalho, dentre outros, disponibilizando para as bancadas da Comissão Permanente Nacional Rural CPNR, quando solicitado. (Alterada pela Portaria MTb n.. 1.086 , de 18 de dezembro de 2018) .Compete ainda à SIT, através do DSST, coordenar, orientar e supervisionar as atividades preventivas desenvolvidas pelos órgãos regionais do 
MTE e realizar com a participação dos trabalhadores e empregadores, a Campanha Nacional de Prevenção de Acidentes do Trabalho Rural - CANPATR e implementar o Programa de Alimentação do Trabalhador - PAT. A SIT é o órgão competente para executar, através das Delegacias Regionais do Trabalho - DRT, as atividades definidas na política nacional de segurança e saúde no trabalho, bem como as ações de fiscalização. 


\section{PROPOSIÇÃO}

Investigar e comparar as condições de saúde auditiva e ambiente de trabalho de agricultores de diferentes lavouras, fumicultores e trabalhadores não expostos a agrotóxico. 


\section{MÉTODOS}

Trata-se de uma pesquisa descritiva, quali e quantitativa e de caráter transversal. Com aprovação do Comitê de Ética em Pesquisa (COMEP), da Universidade Estadual do Centro-Oeste, com número 56772616.1.0000.0106.(ANEXO 1). Para estatística foram utilizadas análises de variância, teste qui quadrado, anova e Kruskal-Wallis.

\subsection{SELEÇÃO DOS PARTICIPANTES}

Foram selecionados trabalhadores rurais de cultivo geral, fumicultores e trabalhadores que não tenham exposição à otoagressores. Esses trabalhadores foram recrutados pelo CEREST (Centro de Referência em Saúde do Trabalhador) da $4^{a}$ Regional do Paraná e a convite da própria pesquisadora. Posteriormente encaminhados a Clínica Escola de Fonoaudiologia (CEFONO), da Universidade Estadual do Centro-Oeste, Irati - PR, local em que a avaliação da audição foi realizada, após assinarem o TCLE (Termo de Consentimento Livre e Esclarecido). (Anexo 2)

Nos critérios de exclusão adotou-se idade maior que 60 anos, presença de corpo estranho ou qualquer alteração no meato acústico externo que impedisse a realização dos exames, presença de perda auditiva do tipo condutiva que não fosse característica de perda auditiva relacionada ao trabalho, problema neurológico e cardíaco e uso de medicação ototóxica referidos na entrevista.

Ao final desta seleção há três grupos sendo:

- GE - Trabalhadores sem exposição à agrotóxico

- GA - Trabalhadores agrícolas de cultivos geral

- GF - Trabalhadores fumicultores

Foram convidados 78 participantes para realizarem a avaliação audiológica proposta para o estudo, 54 aceitaram em primeiro momento, mas apenas 48 compareceram. 3 não concluíram todos os exames por diversos motivos, 1 foi a óbito antes de concluir a bateria de testes ao final do estudo. Ao final GA e GF foram 
compostos por 14 participantes, cada um, e GE por 16. O número de cada grupo foi discutido com o estatístico.

\subsection{PROCEDIMENTOS}

Os procedimentos adotados foram selecionados afim de garantir além da investigação ambiental (entrevista, medição de nível de pressão sonora, levantamento de uso de EPl's e agrotóxicos), a avaliação do sistema auditivo em nível central e periférico (audiometria tonal liminar, logoaudiometria, medida de imitância acústica, emissões otoacústicas evocadas transientes e pesquisa do P300).

Após o recrutamento os participantes foram submetidos aos seguintes procedimentos:

4.2.1 ENTREVISTA 1: primeiramente foi aplicado um questionário elaborado pela própria pesquisadora para analisar a autopercepção dos trabalhadores em relação às substâncias químicas e riscos aos quais estão expostos em seu ambiente de trabalho, assim como rotina de trabalho e hábitos diários voltados a saúde auditiva. Este procedimento foi guiado pela pesquisadora que explicou o questionário com perguntas semiestruturadas ao trabalhador, e então pôde anotar a resposta dada por ele. É determinante que não haja nenhuma dúvida por parte do participante e por isso a pesquisadora esteve disponível para sanar todas as questões que surgirem. (Apêndice 2)

\subsubsection{AUDIOMETRIA TONAL LIMINAR E DE ALTAS FREQUÊNCIAS (ATL}

E AAF): é um exame realizado dentro da cabine acústica, por meio de fones supraaurais (TDH 39) e audiômetro da marca Damplex DA 65. O exame inicia-se na orelha em que o participante referir escutar melhor. O mesmo é orientado a levantar a mão sempre que escutar o estímulo mesmo que com uma intensidade mínima. As frequências testadas na audiometria convencional são de $1000 \mathrm{~Hz}$, $2000 \mathrm{~Hz}, 3000 \mathrm{~Hz}, 4000 \mathrm{~Hz}, 6000 \mathrm{~Hz}, 8000 \mathrm{~Hz}, 500 \mathrm{~Hz}$ e $250 \mathrm{~Hz}$. (LOPES, MUNHOZ e BOZZA, 2015). Porém nessa pesquisa também será realizada a investigação do limiar auditivo na frequência alta de $12,5 \mathrm{kHz}$, pois estas frequências são as primeiras a serem acometidas na maioria das doenças que afetam a orelha interna. 
4.2.3 LOGOAUDIOMETRIA: realizado por meio do audiômetro da marca Damplex DA 65. O teste da logoaudiometria é a medida da habilidade do paciente em reconhecer e detectar a fala. Por meio dele é possível avaliar o Limiar de Deteç̧ão de Fala (LDF), o Limiar de Recepção de Fala (LRF/SRT), e o Índice Percentual de Reconhecimento de Fala (IPRF). O LRF/SRT é pesquisado de acordo com a média dos limiares auditivos de $0,5 \mathrm{kHz}, 1 \mathrm{kHz}$ e $2 \mathrm{kHz}$. Sendo o teste iniciado 30 dBNA acima da média tritonal. A pesquisadora apresenta palavras trissílabas e o paciente é instruído a repetir da forma que entender, sendo que a cada acerto diminui $10 \mathrm{dBNA}$. No primeiro erro, aumenta-se $5 \mathrm{dBNA}$ e apresenta quatro palavras, sendo que se o mesmo acertar $50 \%$ dessas palavras confirma-se o valor do SRT. No IPRF o paciente é solicitado a repetir uma lista de 25 palavras monossílabas em cada orelha, com intensidade fixa em 30 dBNA acima da média tritonal. Cada acerto pontua $4 \%$, dessa forma no final das 25 palavras pode-se realizar um índice de $100 \%$ de acertos. Quando o número de acertos obtidos for inferior a $88 \%$ deve-se realizar o teste com as palavras dissílabas da mesma forma e intensidade. (RUSSO, 2011).

4.2.4 MEDIDAS DE IMITÂNCIA ACÚSTICA: realizado por meio do equipamento AT 235, d

a marca interacoustics é um teste objetivo, indolor, que avalia por meio da colocação de uma sonda na entrada do conduto auditivo externo a integridade da membrana timpânica, as estruturas das orelhas externa e média e o reflexo estapediano que, de forma indireta, verifica as condições das orelhas média e interna. Esse exame é geralmente usado como complementar à audiometria e utilizado para confirmar otites e presença de secreção na orelha média. Podendo ser realizado em qualquer faixa etária. (MELLO, 1999).

\subsubsection{EMISSÕES OTOACÚSTICAS EVOCADAS POR ESTÍMULOS} TRANSIENTES (EOA-t): é um teste que avalia o funcionamento normal da cóclea e da orelha média, verificando a integridade do amplificador coclear. objetivo, rápido e não invasivo. Sendo necessário um ambiente silencioso para a realização do teste, assim como condições favoráveis da orelha externa e média. A marca do aparelho usado para realizar a investigação das emissões otoacústicas dessa pesquisa foi OTOREAD, considerando reprodutibilidade acima de $50 \%$, relação sinal-ruído acima de $3 \mathrm{~dB}$, estabilidade de $80 \%$ e o estímulo em $80 \mathrm{dBNPS}$. 
Em um segundo momento, por motivo do tempo prolongado para a realização desta bateria de exames, os participantes foram submetidos ao exame a seguir:

4.2.6 P300: Conhecido por ser um exame cognitivo uma vez que relacione atenção e discriminação auditiva, esse exame teve o objetivo de avaliar as áreas auditivas cerebrais relacionadas com a capacidade de aprendizado, memorização e atenção. O registro desses potenciais na prática clínica é realizado colocando-se o eletrodo ativo, não invertido, no vértex; o referência no lóbulo ou mastoide do lado a ser testado; e o terra, no lóbulo ou na mastoide contralateral. Faz-se a estimulação por tone burst de $50 \mathrm{~ms}$ de duração, de duas frequências diferentes, no caso 1000 e $2000 \mathrm{~Hz}$, sendo a primeira o estímulo frequente $(80 \%$ de apresentação) e a segunda foi a frequência rara ( $20 \%$ de apresentação) com tempo de análise de 1000 ms. (SOUSA., et al 2010). O paciente foi instruído sobre todos os procedimentos e acontecimentos do exame, além de solicitado a contagem dos estímulos raros percebidos. $O$ estímulo raro deveria ser contado e informado no final do teste. $O$ atraso na latência da onda do P300 ou a ausência desta, poderá indicar um distúrbio do Processamento Auditivo Central. Este teste será realizado por meio do equipamento Contronic.

Para interpretação dos resultados seguiu-se a literatura de Musiek, Baran et al 1994, que propõe que adultos até 45 anos é considerado a latência em 350ms como limite máximo de normalidade. A partir desta idade, adiciona-se $10 \mathrm{~ms}$ a cada década de vida. Dessa forma, seria normal $360 \mathrm{~ms}$ de latência até os 55 anos de idade e $370 \mathrm{~ms}$ até 65 anos.

Com a permissão dos proprietários a pesquisadora fez uma visita ao ambiente de trabalho onde realizou a etapa a seguir:

4.2.7 AVALIAÇÃO AMBIENTAL: Com a finalidade de identificar os riscos que estes trabalhadores estão diariamente expostos, foi feito um levantamento dos produtos químicos presentes nos ambientes laborais e posteriormente estes produtos serão elencados de acordo com seu grau de toxicidade. Além disso, será realizada a medição dos picos de nível de pressão sonora a cada hora, durante uma jornada de 8 horas, nos ambientes de trabalho dos três grupos, com o sonômetro Instrutemp Digital Sound Level Meter. 


\subsection{ANÁLISE DOS RESULTADOS:}

Os dados foram analisados com a intenção de verificar diferença estatisticamente significante entre os grupos deste estudo. 


\section{RESULTADOS}

Para toda e qualquer análise aqui realizada foram consideradas diferenças estatísticas significantes aquelas com $p<0,05$.

Os resultados a seguir representam os achados relacionados à caracterização da amostra e às condições de trabalho de cada grupo.

\subsection{CARACTERIZAÇÃO DA AMOSTRA E ENTREVISTA}

A amostra deste estudo iniciou com 50 trabalhadores, mas por motivos desistência e falecimento, encerrou-se 44 participantes sendo o grupo 1 (GE) composto por 16 trabalhadores de escritório, grupo $2(\mathrm{GA})$ apresenta 14 agricultores de cultivos gerais e por fim o grupo 3 (GF) se compõe com 14 fumicultores. A tabela a seguir mostra a distribuição deste grupo quanto ao gênero e faixa etária.

\begin{tabular}{|c|c|c|c|}
\hline GRUPO & HOMENS & MULHERES & \multicolumn{1}{|c|}{ MÉDIA DE } \\
\hline & IDADE \\
\hline GE & 10 & 6 & 34,43 anos \\
\hline GA & 6 & 8 & 38,85 anos \\
\hline GF & 8 & 6 & 39,21 anos \\
\hline
\end{tabular}

Tabela 1 - Distribuição de gênero e média etária dos grupos 1,2 e 3

O grupo GE composto com maior número de participantes do sexo masculino apresenta uma variação de idade de 20 a 46 anos, sendo o mais jovem do sexo feminino e o mais velho do sexo masculino. $O$ GA encontra-se com o participante mais jovem tendo 23 anos, enquanto o mais velho apresenta 49 anos, ambos do sexo masculino. E por fim o GF tem sua faixa etária distribuída entre 19 a 50 anos 
que também são participantes homens. Não há diferença significante entre as idades.

A jornada de trabalho destes grupos é bastante diferente e podem ser checadas no gráfico 1

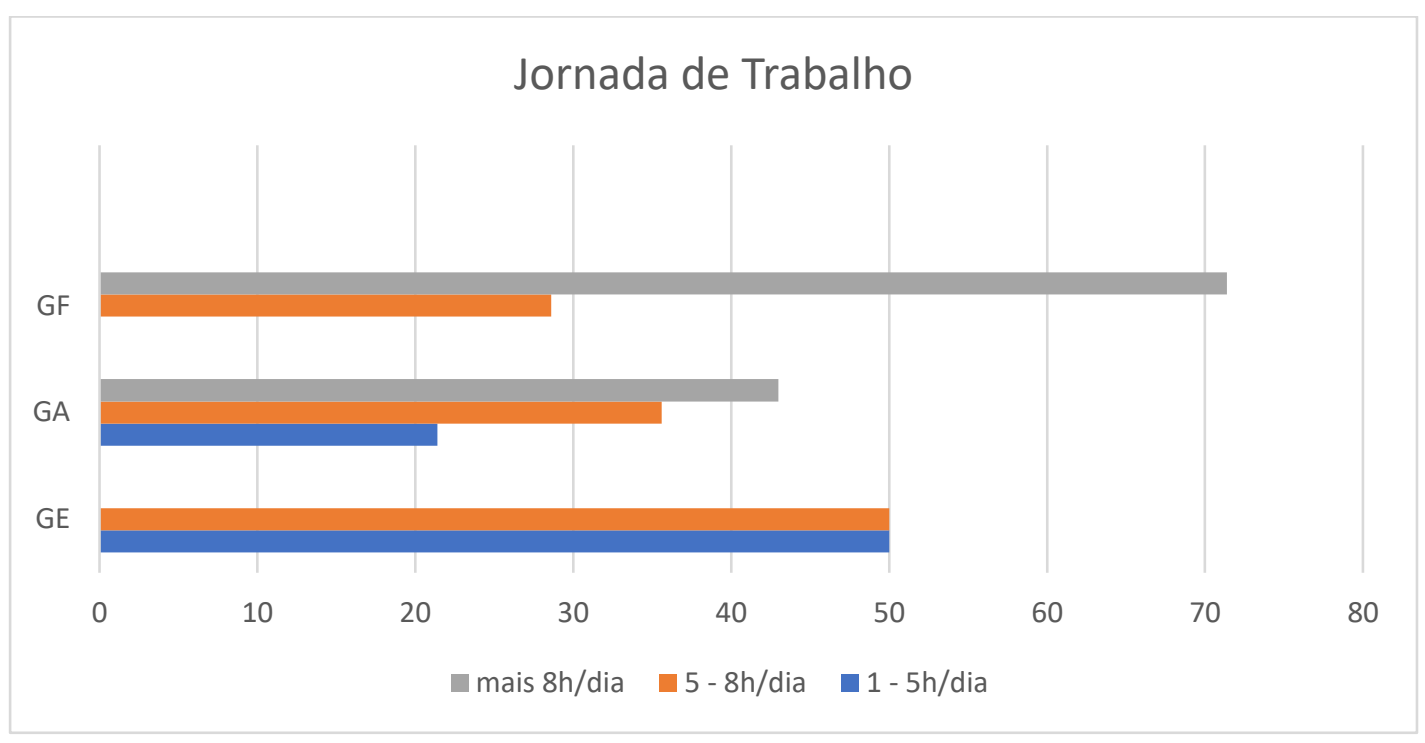

Gráfico1: Porcentagem dos trabalhadores e sua carga horária diária de trabalho.

GE tem 8 trabalhadores que trabalham de uma a cinco horas diárias, e outros 8 que trabalham de cinco a oito horas diárias. GA apresenta 3 trabalhadores que exercem suas funções de três a cinco horas, 5 exercem de cinco a oito horas e 6 que trabalham mais de oito horas diárias. GF tem 4 participantes trabalhando de cinco a oito horas e $10 \mathrm{com}$ carga horária maior que oito horas por dia.

Destes trabalhadores 4 participantes de GE estão nesta função de 1 a 4 anos, o mesmo número de 11 a 15 anos e 8 estão de 6 a 10 anos. GA apresenta apenas um trabalhador nesta função de 1 a 5 anos, enquanto 4 estão de 6 a 10 anos e os 9 restantes trabalham neste ramo há mais de 15 anos. GF tem 2 trabalhadores que se enquadram de 6 a 10 anos e os outros 13 trabalham com fumo há mais de 15 anos. Segundo análise estatística estes dados apresentam diferença entre GA x GE e GF x GA com $p<0,001$. A maior diferença se dá entre GFxGE.

Quando questionados quanto a presença de ruído em seus ambientes de trabalho, os participantes poderiam responder "sim", "não", "as vezes" e "muito". Estas respostas se mostram no gráfico a seguir: 


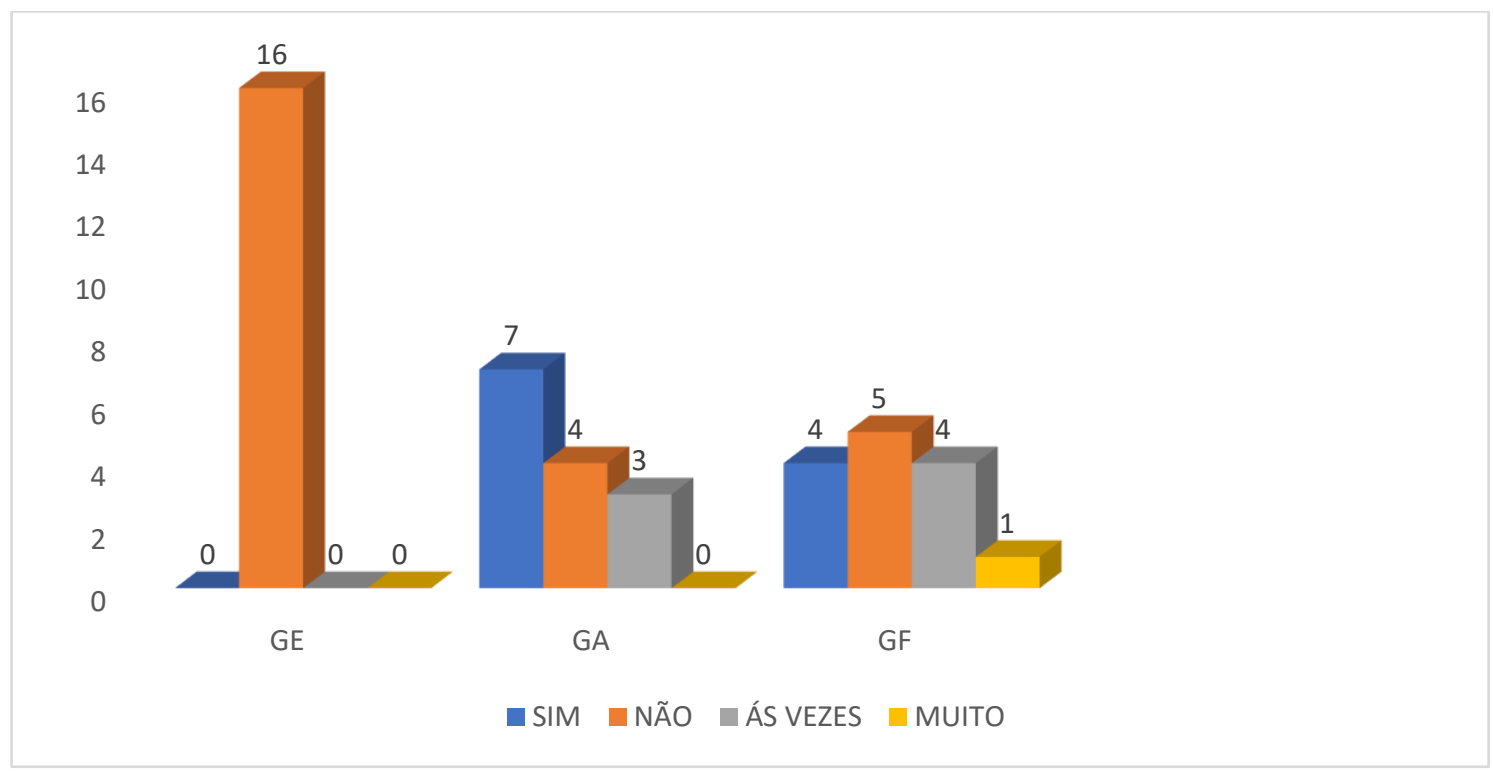

\section{Gráfico 2 - Percepção de Ruído no Ambiente de Trabalho}

Merece destaque o GE que em sua totalidade referiu não trabalhar em ambiente ruidoso. Tanto o GA quanto o GF variaram suas respostas e acrescentaram que este ruído está sempre relacionado ao uso de maquinários e a localidade da propriedade, quanto mais próximo às rodovias maior a percepção de ruído. Com $p<0,05$ a comparação entre estes dados concluiu significância entre GA $x$ GE.

Questionados quanto a relação que se estabelece entre a sua atividade laboral e a sua saúde auditiva, 11 participantes do GE disseram não fazer essa relação, o mesmo número apareceu no GF e no GA 8 trabalhadores não fazem essa relação.

No que se refere a exposição aos agrotóxicos, nenhum participante do GE referiu ter contato com tal agente, por outro lado todos os agricultores e fumicultores relatam contato constante com estes produtos, ou seja, em todos os momentos da lavoura estão em contato com agrotóxicos direta ou indiretamente. Desta forma apenas os componentes dos grupos GA e GF tiveram aptidão para responder quanto ao uso de equipamentos de proteção individual (EPI), tais dados se explanam na tabela a seguir: 


\begin{tabular}{|c|c|c|}
\hline EPI & No em GA & № em GF \\
\hline Bota & 9 & 6 \\
\hline Luva & 6 & 7 \\
\hline Máscara & 3 & 2 \\
\hline Uniforme & 1 & \\
\hline adequado & 0 & 1 \\
\hline Óculos & 0 & 1 \\
\hline Avental & & \\
\hline
\end{tabular}

\section{Tabela2: Levantamento de EPI's}

Chama atenção o fato de tanto GA quanto GF não apresentar nenhum participante que relata ter tido instruções quanto aos males do agrotóxico, assim como a utilização correta dos EPI's. Com isso estes participantes relacionaram queixas de saúde e uso dos insumos e defensivos. O gráfico a seguir demonstra as queixas associadas ao agrotóxico e suas ocorrências.

\section{Queixas}

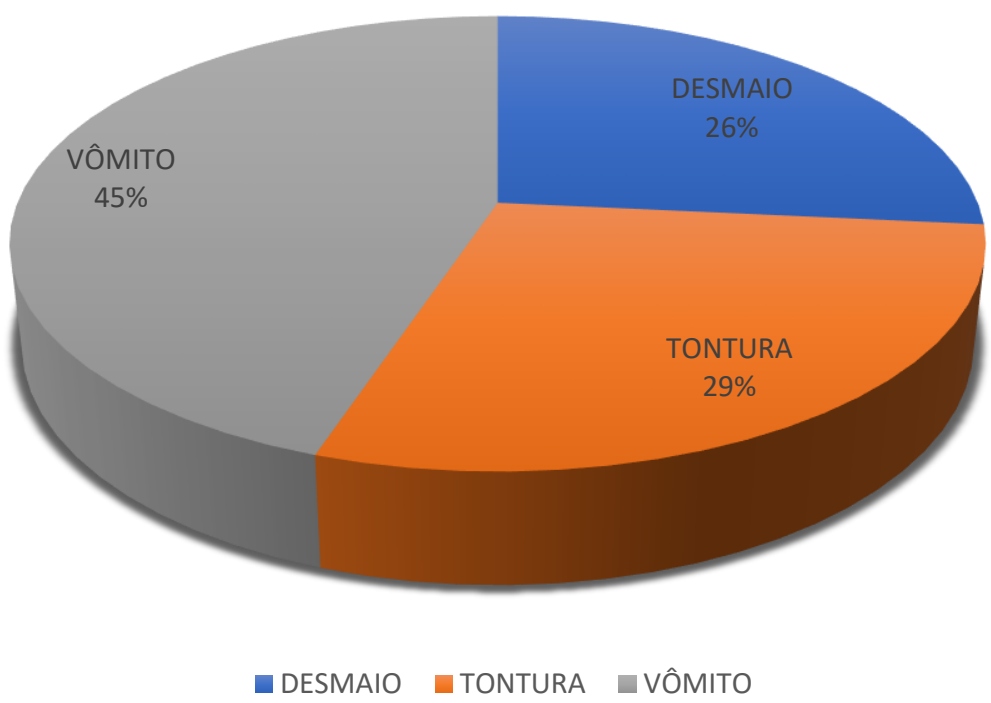

Gráfico 3: Queixas associadas ao uso de agrotóxicos. 
Das queixas relatadas por todos os participantes de GA e GF,13 se referiram ao desmaio, sendo 7 fumicultores e 6 agricultores em geral. Tontura foi uma queixa relatada por 8 participantes de GF e 6 de GA. E o vômito foi apontado por 10 trabalhadores de GA e 12 de GF.

\subsection{AVALIAÇÃO AMBIENTAL}

\subsubsection{MEDIÇÃO DO PICO DE PRESSÃO SONORA}

A medição foi realizada no ambiente de trabalho dos três grupos registrando o pico de pressão sonora de cada hora ao longo de um dia de expediente. Os picos descritos por hora de cada grupo estão especificados na tabela abaixo:

Tabela 3 - Picos de NPS por hora trabalhada

\begin{tabular}{|c|c|c|c|c|c|c|}
\hline & & PICOS & DE & PICOS & $\mathrm{DE}$ & PICOS \\
\hline HORÁRIO & NPS & & NPS & & NPS & \\
\hline & & GE & & GA & & GF \\
\hline 08:00 & & 82,7 & & 71,1 & & 72 \\
\hline 09:00 & & 88 & & 83,2 & & 68,7 \\
\hline $10: 00$ & & 67,9 & & 84,1 & & 73,5 \\
\hline $11: 00$ & & 77,2 & & 86,5 & & 69,2 \\
\hline $12: 00$ & & 84,4 & & 69,2 & & 64,5 \\
\hline $13: 00$ & & 57,5 & & 68,4 & & 58,2 \\
\hline $14: 00$ & & 82,8 & & 88,5 & & 68,9 \\
\hline $15: 00$ & & 59,9 & & 79,4 & & 72,9 \\
\hline $16: 00$ & & 89,2 & & 78,5 & & 84,8 \\
\hline $17: 00$ & & 83,8 & & 71,7 & & 88,9 \\
\hline
\end{tabular}


18:00

MÉDIA
80,6

77,6363636
65,4

76,9090909

1
75,7

72,4818181
4

8

A maior média registrada foi atribuída ao ambiente de trabalho do GE que teve sua variação entre 57,5 e 89,2dBNPS, a segunda maior média aconteceu no GA que teve seus picos variando entre 65,4 e 88,5 dBNPS. Já o GF apresentou menor média de picos e suas variações aconteceram entre 58,2 e 88,9 dBNPS. Ainda que apresentem médias diferentes, estes ambientes apresentaram níveis de pressão sonora bastante parecidos comprovados por $p>0,005$.

Ao que se refere aos agrotóxicos, foram listados doze nomes que são rotineiramente usados, a tabela a seguir mostra quais são, quais grupos usam e qual é a classificação toxicológica de cada um deles.

\begin{tabular}{|c|c|c|c|}
\hline AGROTÓXICO & $\begin{array}{l}\text { QUEM } \\
\text { USA }\end{array}$ & CLASSIFICAÇÃO & STATUS \\
\hline Roundup & $\mathrm{GF} \quad \mathrm{GAe}$ & $\begin{array}{l}\text { III - Medianamente } \\
\text { Tóxico }\end{array}$ & Liberado \\
\hline 24D Nortóx & GA & Tóxico & $\begin{array}{l}\text { Liberado com } \\
\text { restrição }\end{array}$ \\
\hline Ally & GF & Tóxico & $\begin{array}{l}\text { Liberado com } \\
\text { restrição }\end{array}$ \\
\hline Fox & GA & Tóxico & Liberado \\
\hline $\begin{array}{l}\text { Confidor } \\
\text { Supra }\end{array}$ & GF & Tóxico III - Medianamente & Liberado \\
\hline Orthene & GF & Tóxico & $\begin{array}{l}\text { Liberado com } \\
\text { restrição }\end{array}$ \\
\hline Talstar & GF & T̄óxico & Liberado \\
\hline
\end{tabular}




\begin{tabular}{|c|c|c|c|c|}
\hline PrimerPlus & GF & Tóxico & III - Medianamente & Liberado \\
\hline Grant & GF & Tóxico & I - Extremamente & Liberado \\
\hline Boral $500 \mathrm{C}$ & GF & Tóxico & II - altamente & $\begin{array}{l}\text { Liberado com } \\
\text { restrição }\end{array}$ \\
\hline Rovral & GF & Tóxico & I- Extremamente & Liberado \\
\hline Glifos & $\begin{array}{l}\text { GAe } \\
\text { GF }\end{array}$ & Tóxico & II - altamente & $\begin{array}{l}\text { Liberado com } \\
\text { restrição }\end{array}$ \\
\hline
\end{tabular}

Quadro 3: Distribuição dos agrotóxicos mencionados

Dos doze compostos citados, apenas dois não foi referido uso na fumicultura, fazendo com que GF esteja em maior contato com estes produtos durante seu período de trabalho.

Os próximos resultados referem-se exclusivamente aos achados audiológicos deste estudo.

\subsection{ACHADOS AUDIOLÓGICOS}

5.3.1 Audiometria Tonal Limiar e de Altas Frequências (ATL e ATF)

Todos os participantes não apresentaram qualquer impedimento para realização do exame. Foi realizada a pesquisa de via óssea indicando comprometimento sensorioneural. As médias dos limiares obtidos em cada grupo encontram-se detalhadas no gráfico a seguir: 


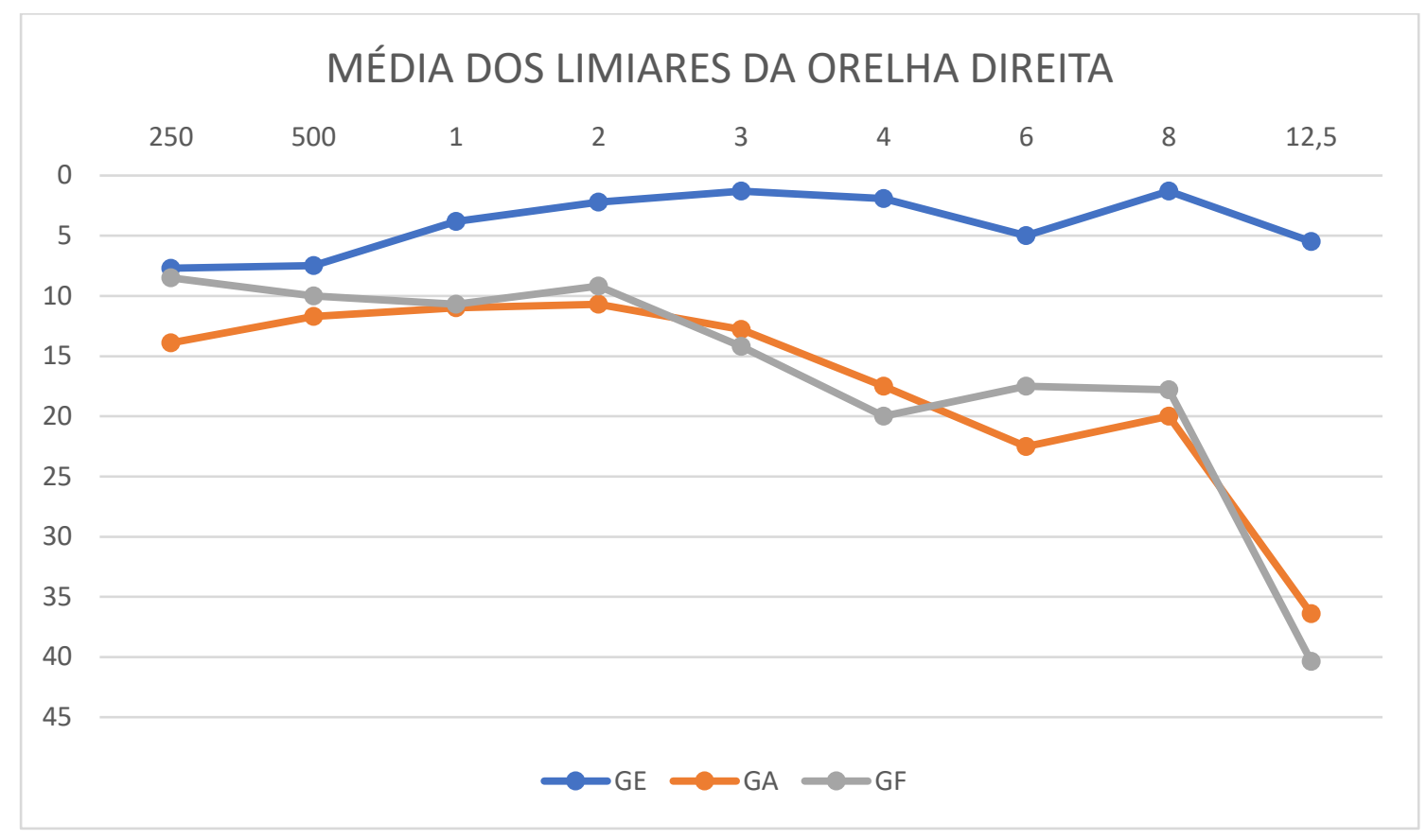

Gráfico 4: MÉDIA DOS LIMIARES DA ORELHA DIREITA

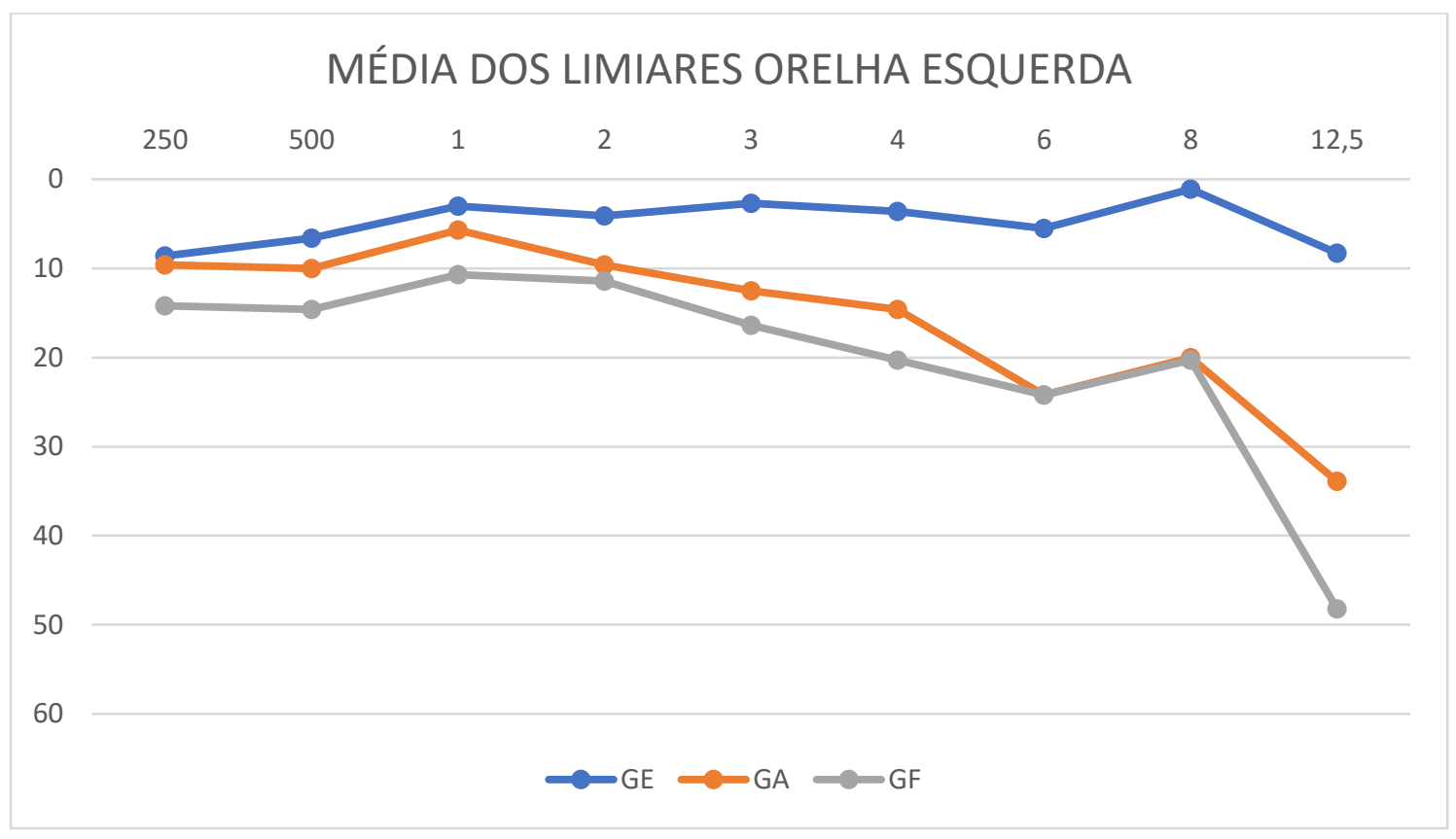

Gráfico 5: MÉDIA DOS LIMIARES DA ORELHA ESQUERDA

A frequência com maior limiar auditivo em todos os grupos foi a de $12,5 \mathrm{kHz}$. No GE a segundo frequência com menor desempenho foi a de $250 \mathrm{~Hz}$ com uma média de 7,7 na OD e 8,6 na OE. Já no GA e no GF as frequências mais 
comprometidas, após $12,5 \mathrm{kHz}$, foram as frequências de 4 e $6 \mathrm{kHz}$ onde os limiares estiveram acima de $20 \mathrm{~dB}$ nos dois grupos.

Análises estatísticas puderam comprovar que GA e GF apresentaram piores rendimentos, com $\mathrm{p}<0,05$, nas frequências de $1 \mathrm{kHz}, 2 \mathrm{kHz}, 3 \mathrm{kHz}, 6 \mathrm{kHz}, 8 \mathrm{kHz}$ e ar que tal diferença estatística na frequência de $4 \mathrm{kHz}$ aconteceu apenas com a relação GF $\times$ GE,

O quadro a seguir demonstra a variação de limiares por frequências apresentando os valores mínimos e máximos encontrados em cada grupo.

\begin{tabular}{|c|c|c|c|c|c|c|c|c|c|c|c|c|c|c|c|c|c|c|}
\hline & \multicolumn{2}{|c|}{250} & \multicolumn{2}{|c|}{500} & \multicolumn{2}{|c|}{1} & \multicolumn{2}{|c|}{2} & \multicolumn{2}{|c|}{3} & \multicolumn{2}{|c|}{4} & \multicolumn{2}{|c|}{6} & \multicolumn{2}{|c|}{8} & \multicolumn{2}{|c|}{12,5} \\
\hline & MIN & MÁX & MIN & MÁX & MIN & MÁX & MIN & MÁX & MIN & MÁX & MIN & MÁX & MII & MÁX & MIN & MÁX & MIN & $\mathbf{M A}$ \\
\hline $\mathrm{GE}$ & 5 & 20 & 0 & 20 & -5 & 15 & -10 & 10 & -5 & 15 & -10 & 15 & -5 & 20 & -10 & 15 & -5 & 2 \\
\hline GA & 5 & 30 & 5 & 25 & 0 & 40 & 0 & 45 & 0 & 55 & 5 & 70 & 5 & 75 & 5 & 65 & 5 & \\
\hline GF & -5 & 30 & 0 & 25 & 0 & 25 & 0 & 35 & 0 & 45 & 5 & 50 & 5 & 40 & -5 & 35 & 15 & \\
\hline$P<0,05$ & & & & & $\mathrm{p}=0$, & & $p<0$ & & $\mathrm{p}<0$, & & $\mathrm{p}<0$, & & & & $\mathrm{p}=0$ & & & 0,001 \\
\hline
\end{tabular}

Tabela 4: Limiares mínimos e máximos da OD, de GE, GA e GF; valor de p para cada frequência.

\begin{tabular}{|c|c|c|c|c|c|c|c|c|c|c|c|c|c|c|c|c|c|c|}
\hline & \multicolumn{2}{|c|}{250} & \multicolumn{2}{|c|}{500} & \multicolumn{2}{|c|}{1} & \multicolumn{2}{|c|}{2} & \multicolumn{2}{|c|}{3} & \multicolumn{2}{|c|}{4} & \multicolumn{2}{|c|}{6} & \multicolumn{2}{|c|}{8} & \multicolumn{2}{|c|}{12,5} \\
\hline & MIN & MÁX & MIN & MÁX & MIN & MÁX & MIN & MÁX & MIN & MÁXX & MIN & MÁX & MIN & MÁX & MIN & MÁX & MIN & MÁX \\
\hline GE & -5 & 20 & -5 & 20 & -10 & 15 & -10 & 25 & -5 & 15 & -5 & 20 & -5 & 20 & -10 & 20 & 0 & \\
\hline GA & -5 & 25 & 0 & 25 & 0 & 15 & 0 & 20 & -5 & 45 & -5 & 40 & -5 & 55 & -5 & 50 & -5 & \\
\hline GF & 0 & 45 & -5 & 50 & 0 & 30 & -5 & 40 & -10 & 50 & -5 & 50 & 5 & 60 & 0 & 55 & 15 & \\
\hline $\mathrm{P}<0,0$ & & & & & & & &, 008 & &, 018 & &, 009 & & 0,001 & &, 005 & & \\
\hline
\end{tabular}

Tabela 5: Limiares mínimos e máximos da OE, de GE, GA e GF; valor de p para cada frequência.

$\mathrm{Na}$ OD o menor limiar encontrado foi de $-10 \mathrm{dBe}$ pertence ao GE, já o maior limiar encontrado pertence ao GF e foi de $70 \mathrm{~dB}$. O mesmo acontece com a $\mathrm{OE}$ onde o menor limiar, também do GE é de -10 dB e o maior limiar também é do GF e atinge $100 \mathrm{~dB}$. Na análise estatística em todas as frequências GF se distancia mais do GE o que o transforma no grupo com piores limiares. 


\subsubsection{LOGOAUDIOMETRIA}

A grande maioria dos participantes atingiram a porcentagem considerada dentro dos padrões normais para o índice de reconhecimento de fala, apenas 5 orelhas apresentam pontuação abaixo do esperado, que seria de até $92 \%$ de acertos. O quadro abaixo explana a distribuição destas pontuações:

\begin{tabular}{|c|c|c|c|c|c|c|c|c|c|c|c|c|}
\hline$\%$ & \multicolumn{2}{|c}{100} & \multicolumn{2}{c|}{96} & \multicolumn{2}{c|}{92} & \multicolumn{2}{c|}{84} & \multicolumn{2}{c|}{80} & \multicolumn{2}{c|}{76} \\
\hline & OD & OE & OD & OE & OD & OE & OD & OE & OD & OE & OD & OE \\
\hline GE & 11 & 12 & 4 & 6 & 1 & & & & & & & \\
\hline GA & 10 & 8 & 3 & 3 & & 3 & & & & & & 1 \\
\hline GF & 10 & 9 & 2 & 2 & & 1 & & 1 & 1 & 1 & 1 & \\
\hline
\end{tabular}

Quadro 4: Porcentagem de acertos por orelha

GE apresentou todas as orelhas testadas com pontuações dentro do padrão de normalidade, GA apresentou uma orelha esquerda com escore inferior ao esperado atingindo $76 \%$ de acertos e por fim, GF apresentou 4 orelhas com número de acerto abaixo do esperado.

\subsubsection{MEDIDA DE IMITÂNCIA ACÚSTICA}

Todas as curvas timpanométricas dos 44 participantes foram do tipo "A" e resposta dentro do esperado para a pesquisa ipsilateral. Dois trabalhadores de GF e um trabalhador de GA não apresentaram resposta de reflexo estapediano em pesquisa contralateral.

\subsubsection{EMISSÕES OTOACÚSTICAS EVOCADAS TRANSIENTES}

O gráfico a seguir demonstra a média de reprodutibilidade de cada grupo por frequência, demonstrando que o grupo que apresenta maior funcionalidade de células ciliadas é GE seguido de GA e GF. Destaca-se ainda que esta funcionalidade se torna ainda mais deficitária nas altas frequências, e isso acontece em todos os grupos. 


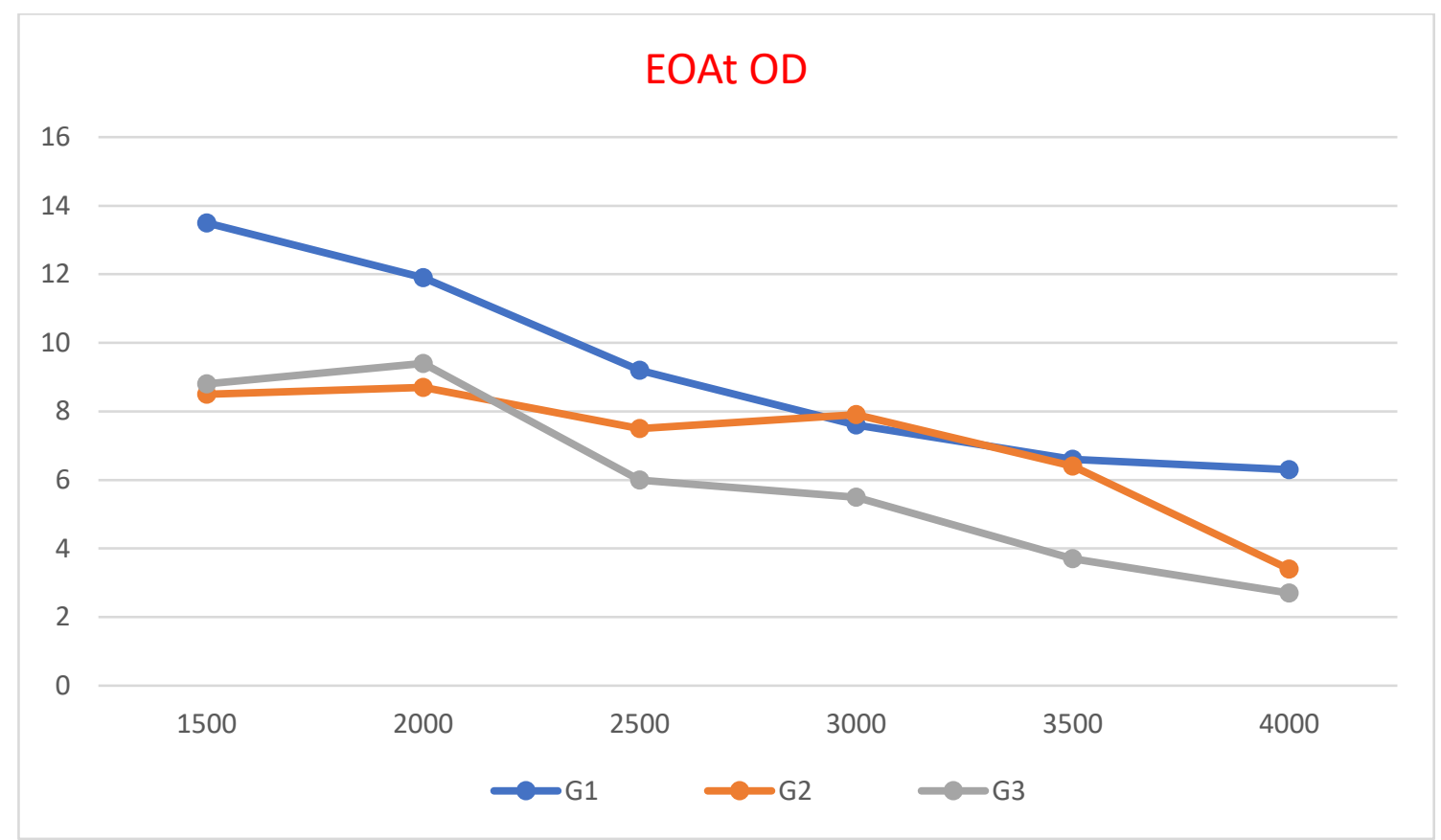

Gráfico 6: Média dos resultados de EOAt, por frequência, na OD.

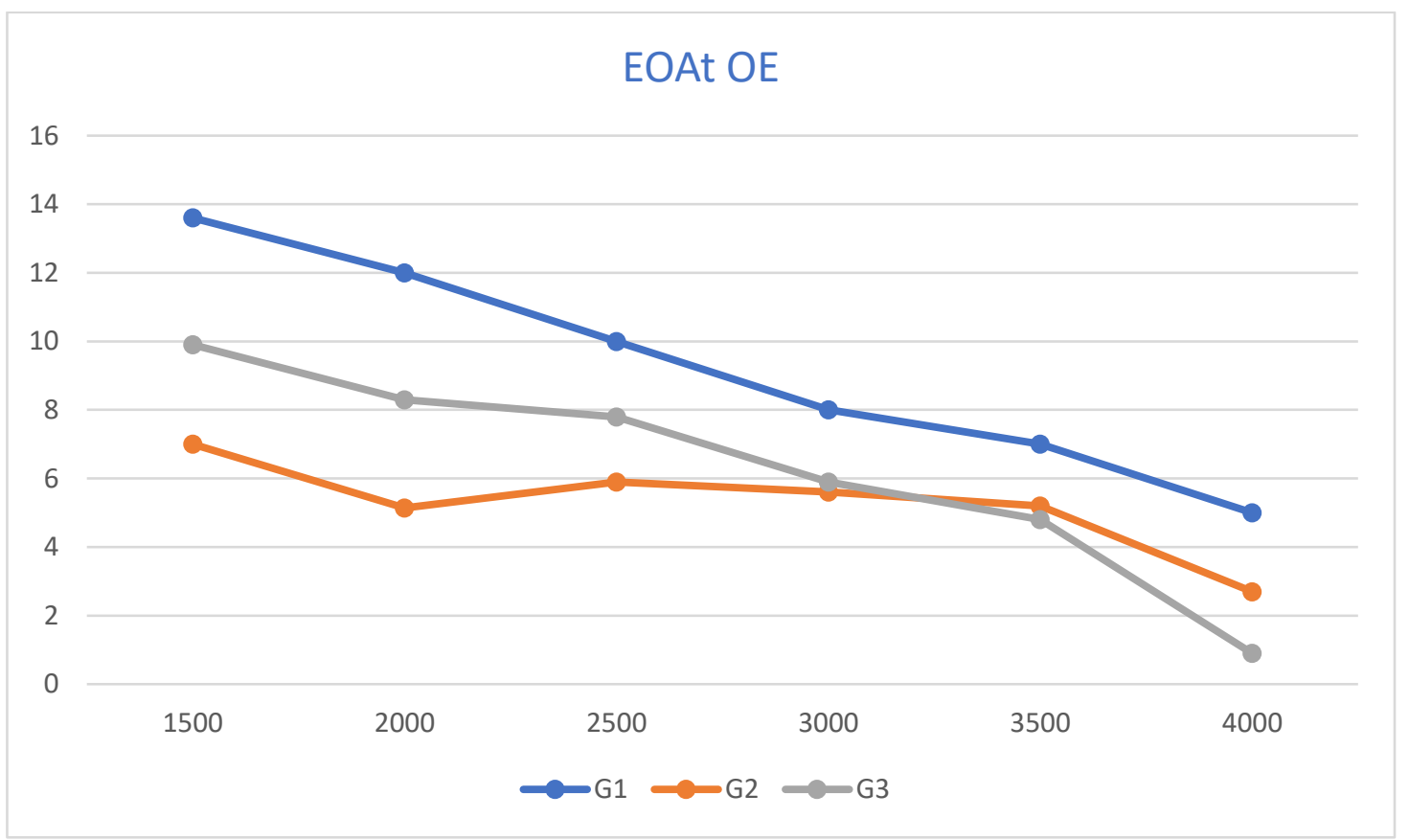

Gráfico 7: Média dos resultados de EOAt, por frequência, na OE.

O menor sinal de funcionalidade de células ciliadas externas aconteceu na frequência de $4 \mathrm{kHz}$ na OE do GF atingindo uma média de 0,9. 
Em contrapartida o maior sinal ocorreu em $1500 \mathrm{~Hz}$ da $\mathrm{OE}$ do $\mathrm{GE}$, atingindo 13,6 .

Quando comparado estatisticamente, pôde-se obter resultados com diferença significante apenas nas frequências de 1500, na OD com $p=0,05$; e em 1500, 2000 e $4000 \mathrm{~Hz}$ na OE, com $p=0,59, p=0,67$ e $p=0,52$, respectivamente.

\subsubsection{P300}

Destaca-se neste teste a dificuldade encontrada para realização do mesmo nos grupos GA e GF. Apesar da explicação persistente e diversos casos de reteste, um participante do GF de 50 anos, não conseguiu realizar o exame por relatar não conseguir diferenciar os estímulos apresentados. Este participante foi mantido em consideração a análise estatística*.

GE não apresentou dificuldade alguma e também não houve casos de latência alterada nos registros da onda. Já GA apresentou quatro participantes com latência aumentada e GF contou com cinco participantes com a mesma alteração, todos os casos com correção segundo idade. Tanto para OD como para OE, GA e GF apresentam p<0,05 quando comparados a GE.

Nas tabelas abaixo conseguimos observar a relação idade e latência da onda P300, assim como a observação de esperado ou alterado.

Tabela 6: Latências registradas no potencial 300

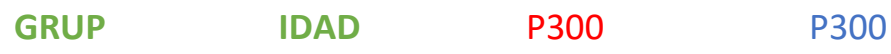

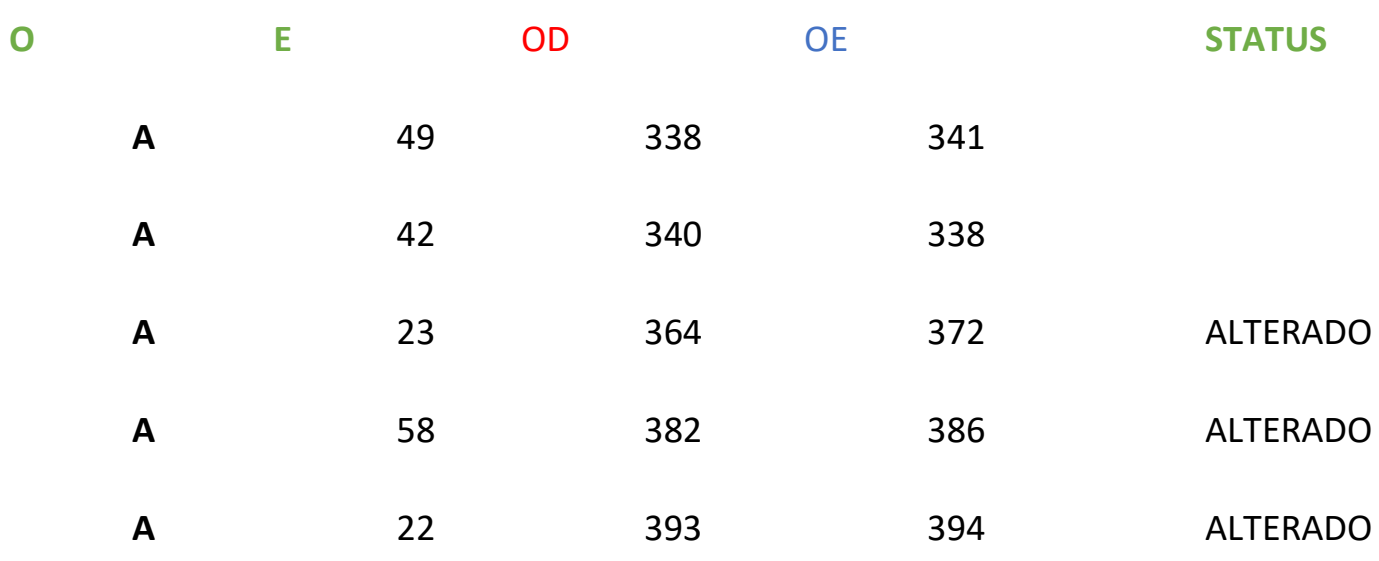




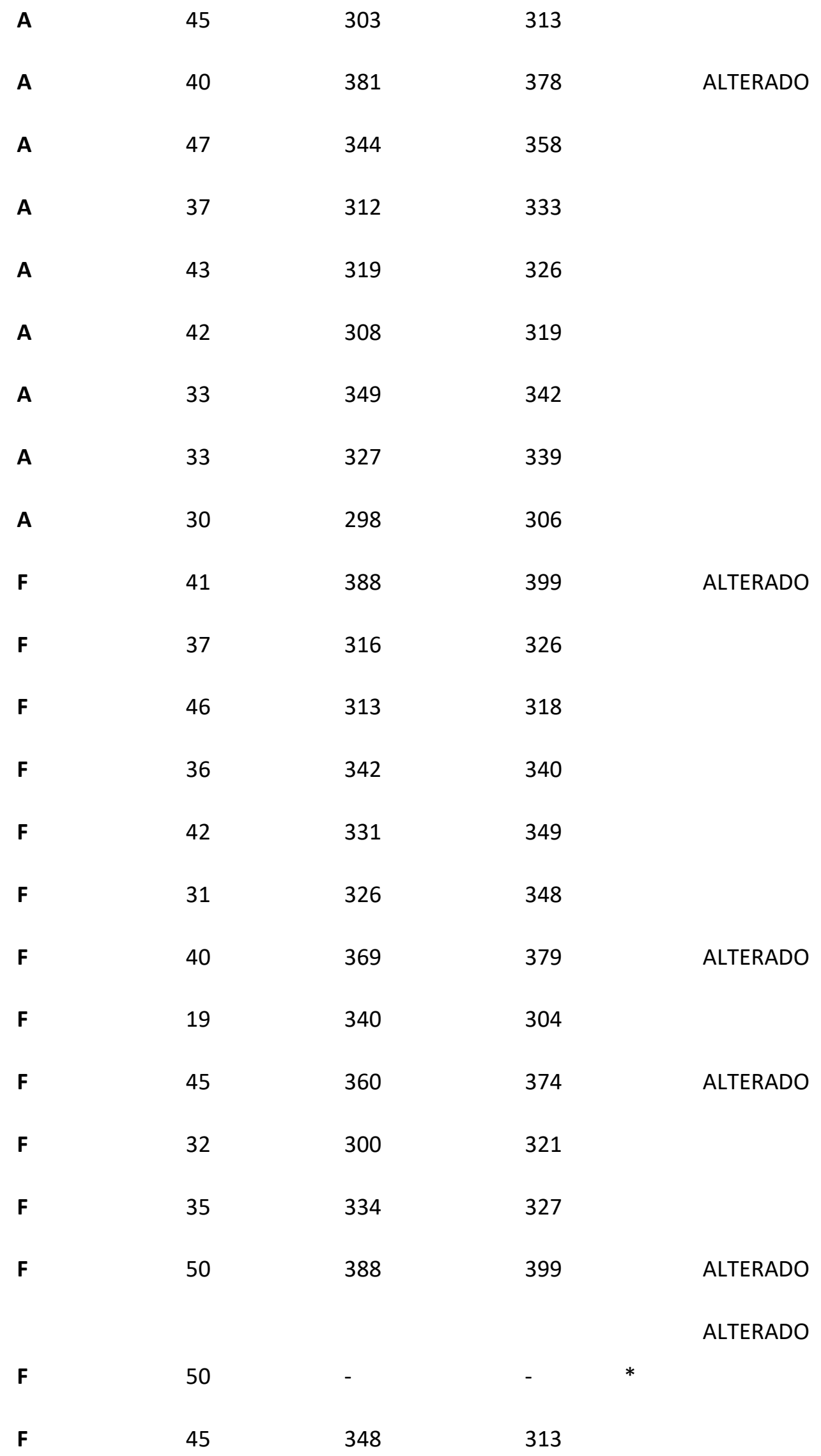




\section{DISCUSSÃO}

Para que as comparações aconteçam sem interferência de sexo e/ou idades este estudo buscou parear tais características e ao final obteve-se 24 homens e 20 mulheres, com idades variando de 19 a 50 anos e com a média da faixa etária similares entre os grupos.

A jornada de trabalho mais flexível aconteceu no GE que apresentou seu teto de horas trabalhadas diárias em $8 \mathrm{~h}$. Isso deve acontecer por se tratar de um ambiente de trabalho reconhecido e registrado pelas leis trabalhistas. $\mathrm{Na}$ Consolidação das Leis Trabalhistas (CLT) está previsto que o máximo de horas a serem trabalhadas, no período de uma semana, deverá ser de 44 horas. A CLT de 2017 diz ainda que a distribuição deste total poderá até ser de 12horas por dia, desde que haja 36horas de descanso após. Pode-se ainda acrescer 4 horas de horas extras semanais. (CONSOLIDAÇÃO DAS LEIS TRABALHISTAS, ATUALIZAÇÃO NO ANO DE 2017. ARTIGO 59-A.). Essa flexibilidade pode acontecer para o aumento ou para diminuição de horas trabalhadas, sendo necessário acordo entre empregado e empregador. Por se tratarem de trabalhadores não regulamentados, sendo na maioria das vezes cultivos familiares, os agricultores e fumicultores não participam das regras da CLT o que faz com que a carga horária não tenha limites e isso pode justificar o aumento das horas trabalhadas num dia. GF apresenta o maior número de trabalhadores com carga superior à $8 \mathrm{~h} / \mathrm{dia}$, segundo relato isso acontece pois o próprio cultivo do fumo exige manuseio no período diurno e noturno. Por exemplo, segundo Brasil (2007) podemos destacar dois tipos de tabacos o Tabaco de Estufa (TE) que são os fumos claros, com folhas submetidas à cura em estufas com temperatura $\mathrm{e}$ umidade controladas (flue cured), num processo que demanda cerca de 5 a 7 dias para ser concluído. Um exemplo é o fumo Virgínia, que representa cerca de $84 \%$ do volume produzido; e o Tabaco de Galpão (TG) - São fumos escuros, curados em galpões ventilados naturalmente, que levam cerca de 40 dias para completar o processo de cura. As variedades desse grupo são o Burley e o Galpão Comum, que participam com aproximadamente $14 \%$ e $2 \%$, respectivamente, do total de fumo produzido. O primeiro deles, por apresentar um curto tempo de maturação precisa de atenção em tempo integral para controle de pragas, pestes e para o 
próprio processo de secagem. Neste tipo de cultivo o trabalhador irá se dedicar por mais de 8 h diárias.

O cultivo familiar também pode explicar o fato de haver sujeitos com idade acima de 15 anos em contato com este trabalho, mesmo que a idade não seja elevada. Acontece que a fumicultura é também considerada uma tradição familiar na região deste estudo, e isto acarreta no início das atividades laborais ainda no período infantil. No convívio destes trabalhadores foram observadas crianças de até 6 anos inseridas no processo de plantio e colheita do fumo. No setor agrícola geral havia crianças apenas na colheita.

Este estudo se preocupou também em avaliar o ambiente no que se refere aos níveis de pressão sonora e à percepção que os trabalhadores têm em relação a este aspecto.

O ruído geralmente é definido como uma energia acústica audível que pode ser prejudicial tanto ao bem-estar fisiológico quanto psicológico das pessoas, sendo, muitas vezes associado a um som indesejável. É também considerado o fator etiológico mais prevalente nas doenças ocupacionais e na perda auditiva induzida por ruído. (ANDRADE, LIMA E SOARES, 2015).

A percepção do incômodo depende de cada pessoa, mas existem regras gerais. Ruídos de alta frequência, alta intensidade, desconhecidos e descontínuos incomodam mais (ARALDI, 2004). Neste sentido, buscando associação, teve-se a intenção de associar qual é a percepção de ruído dos trabalhadores em seus ambientes laborais e após, medir o real nível de pressão sonora nestes locais. GE foi o único grupo com resposta unânime de ausência de percepção do ruído, GA teve suas respostas divididas entre haver percepção de ruído, haver percepção as vezes e não haver. GF acompanha GA, mas acrescenta uma resposta com percepção de ruído intenso.

Gosling.M; Araújo.GCD. (2008) estudaram os níveis de pressão sonora de trabalhadores agrícolas e obtiveram um ruído equivalente a 94,4 dB(A) para uma jornada de 8 horas por dia. Esse valor excede o limite de $85 \mathrm{~dB}(\mathrm{~A})$ estabelecido para uma jornada sem proteção auditiva. Conclui-se que o trabalhador pesquisado sofre um nível de pressão sonora acima do estabelecido na legislação vigente brasileira. Ressaltaram que Máquinas agrícolas (tratores) 
geram um ganho em termos de produtividade, mas geram riscos laborais potenciais, perturbando a saúde dos trabalhadores rurais.

O ruído como fator de risco, em trabalhos com máquinas (por exemplo, tratores) pode trazer perda da audição, além de distúrbio do sono, nervosismo, alterações gastrointestinais, doenças do sistema cardiovascular (hipertensão arterial e doença isquêmica do coração), endócrino, metabólico, e neurológico (DIAS, 2006, REGAZZI et al., 2004, AZEVEDO, 2004). Assim, segundo Rodrigues (2004), as ações do ruído sobre o organismo humano podem ser agrupadas em: a) efeitos sobre o organismo em geral (perturbar circulação sanguínea e provocar efeitos psicológicos, como o stress); b) efeitos sobre rendimento do trabalho (fadiga, falta de atenção, trazendo prejuízos para qualidade do produto e desperdício de tempo e material); c) a ocorrência de acidentes (causa indireta).

Durante a avaliação ambiental (medição dos picos de pressão sonora) no ambiente do GE foram detectados, prevalentemente, sons de conversa, impressoras, telefone e ventiladores. Os níveis variaram de 57,5 a 89,2 dB. Estes níveis foram bastante similares com os encontrados em GF, 58,2 a 88,9dB, sendo que durante a avaliação observou-se apenas conversas, rádio e caminhões como fontes geradoras de sons. No ambiente de GA, bastante parecido com GF, os níveis ficaram entre 65,4 e 88,5 dB. Teve como diferença a presença de tratores. No geral, os três ambientes não tiveram diferença significativa entre os NPS, apesar de haver grande diferença entre as percepções do ruído. Segundo relato dos próprios trabalhadores a percepção pode ser subjetiva e estar vinculada apenas aos sons que não fazem parte do dia a dia de cada um fora do ambiente de trabalho. O toque do telefone, presente em qualquer ambiente, no GE, atingiu 89,2 dB e não foi considerado em nenhum momento como ruído. Já o som do motor do trator, presente apenas no ambiente laboral, atingiu $88,9 \mathrm{~dB}$, e foi considerado como ruído intenso.

O aumento do uso de maquinários acompanha a crescente demanda no setor agropecuário, logo a preocupação com a segurança deste setor também aumenta. Apesar do tema de gestão de saúde e segurança do trabalho estar sendo cada vez mais investigado no contexto acadêmico-científico, como atesta Mendes (2003), nota-se a relativa escassez de análises focadas no trabalhador rural. Quando existem, grande parte dos estudos sobre segurança do trabalho em 
atividades rurais trata das consequências do manuseio de agrotóxicos, como em Borges, Dal Fabbro, Rodriguez (2004); Levigard (2001); Stoppelli (2005); Soares (2001); Kotaka (2005) e Mendonça, Marinho (2005). Há de se pensar que a segurança deve também abordar outros aspectos como uso de EPIs não restritos aos agentes químicos. Este estudo investigou a prática dos trabalhadores rurais quanto ao uso destes equipamentos e não houve nenhum relato de uso de protetor auricular e apenas um sujeito, de GA, referiu usar o uniforme completo.

Em um de seus boletins mensais a Câmara Setorial de Maquinas e Implementos Agrícolas Da Abimaq, em janeiro de 2013 emitiu uma nota em que Associados da CSMIA-ABIMAQ estaria ajudando a disseminar proteção para operadores de equipamentos, nela foram descritas as preocupações quanto aos números de intoxicações e ainda ressaltou-se a importância da conscientização do uso adequado de EPIs com imagem assertivas. No entanto, em nenhum momento abordou-se o uso de protetores auriculares.

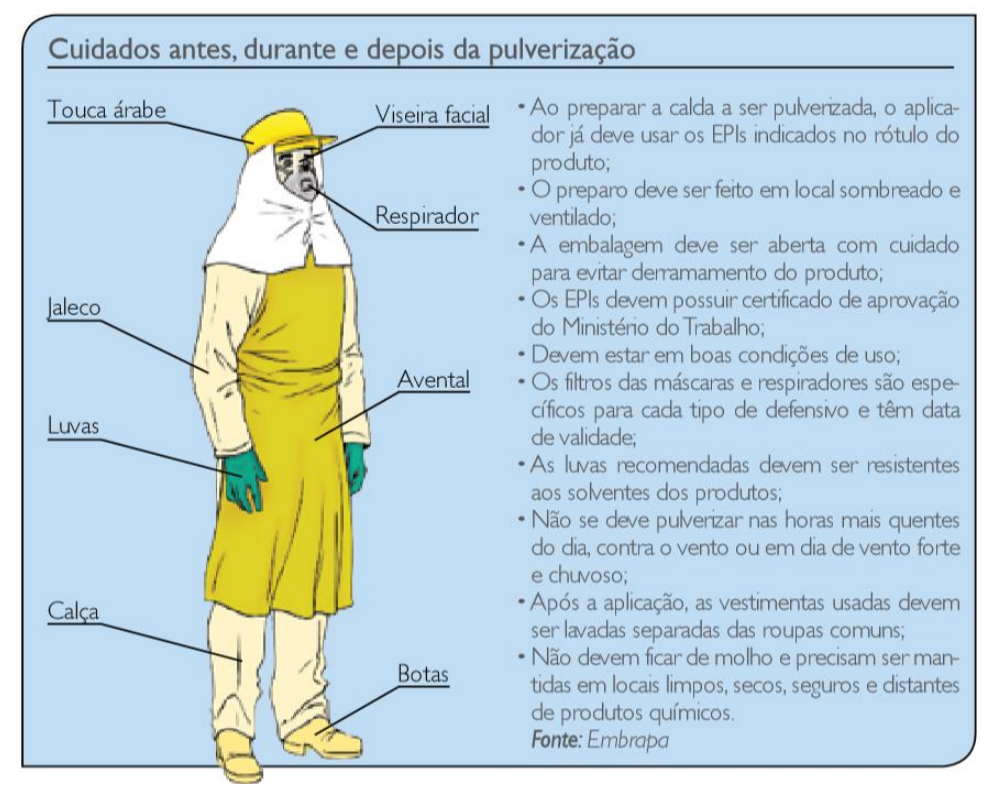

Figura 2: Uso e manuseio correto de EPI's

O estudo de França (2013) corrobora com esse no que se diz respeito a ausência de uso de protetores auriculares, mas há diferença na frequência de uso dos outros EPIs. Relata que os EPIs mais referidos foram: as botas $86,0 \%$; a luva usada por $86 \%$ dos fumicultores, o boné usado por $82,0 \%$, a máscara usada por $68,0 \%$ dos entrevistados e o macacão referido como usado por $41,0 \%$ dos 
fumicultores. No presente estudo a maior justificativa, coletada em campo, quanto ao não uso de EPI foi o desconforto que eles carregam. De acordo com Lima (2004) o principal problema relatado é o mal-estar decorrente do calor provocado pelo uso do EPI. Tal queixa também foi referida pelos fumicultores deste estudo. Manjabosco, Morata e Marques (2004), lembram que há obrigatoriedade quanto ao fornecimento de EPI pelas empresas, segundo o Ministério do Trabalho e Emprego, na Norma Regulamentadora NR 6, mas que no estudo realizado por eles com trabalhadores agrícolas, embora a empresa forneça os EPI, somente $21 \%$ dos sujeitos estudados, disseram usá-los, sempre, no trabalho. Tanto em GA quanto em GF a maioria dos trabalhadores além de não fazer o uso dos equipamentos, ainda apresentaram o costume de transitar entre ambientes casatrabalho com as mesmas vestimentas. A higienização também foi precária e não houve a preocupação de não contaminação dos ambientes. Tais dados corroboram com o estudo de Buaski et al., 2018, que apontou que a higienização de roupas utilizadas para aplicação de agrotóxicos, em um grupo de fumicultores, é um meio indireto de exposição/contaminação pelos agrotóxicos e/ou substâncias químicas. Estas condições são agravadas pelo fato de não haver uma vigilância permanente.

Diferentemente dos trabalhadores industriais que estão constantemente sob monitoramento e normas da CLT, os trabalhadores deste estudo advêm de grupos de baixo nível instrucional, sem qualquer monitoria e/ou normas trabalhistas vigentes. Schlindwein (2010) ressalta que na definição de papéis impostos ao trabalhador rural no âmbito familiar há necessidade de constante força física para o trabalho, o adoecimento pode sobrecarregar outros membros e comprometer a subsistência da família. Nesta amostra, o uso de EPI foi muitas vezes associado às quedas de rendimento no trabalho, e por isso abolido das práticas.

Sem o uso de proteção e com o uso desenfreado de agentes agressores a influência na qualidade de vida e na saúde geral dos trabalhadores acaba se potencializando. Siqueira et al., (2013) realizou estudo com 343 trabalhadores sendo um grupo exposto a agrotóxicos e outro não e concluiu que aqueles que estão expostos apresentam pior índices de qualidade de vida. Pesquisadores concordam que a qualidade de vida de um indivíduo pode sofrer interferências ou 
se associarem às diferentes áreas de trabalho e atividades, já que fatores como os sociais, econômicos, tecnológicos e orgânicos no ambiente laboral podem ser decisivos por atuarem diretamente no estado psíquico do trabalhador. (PAULA ET AL.,2015; SILVA ET AL.,2014). Logicamente pessoas que apresentam maiores queixas relacionadas a saúde apresentam também menor qualidade de vida quando comparadas àquelas sem queixas. Neste estudo foram levantadas queixas relacionadas às atividades laborais e o grupo que mais pontuou foi GF seguido de GA. GE não apresentou queixas. Das queixas apresentadas o vômito foi o mais elencado sendo 12 integrantes de GF e 10 do GA. Segundo o site da CETESB do Governo do Estado de São Paulo (2019), em seu guia de identificações de intoxicações e contaminações, o trato gastrintestinal é a entrada principal de substâncias ambientais presentes nos alimentos, na água, no solo e em aerodispersóides.

As substâncias muito cáusticas, como o hidróxido de sódio, quando ingeridas podem causar um efeito grave no trato gastrintestinal já que alteram a constituição química das células das membranas. Essa alteração comumente é percebida com sequências de vômitos.

Destaca-se ainda o que os trabalhadores de GF relataram a rotina de tomar leite puro antes e após contato com o cultivo afim de prevenir maiores episódios de vômitos. A tontura esteve presente em 14 dos 28 trabalhadores de GA e GF, 8 eram de GF. Este último sintoma está diretamente relacionado aos desmaios relatados, pois apenas um que relatou tontura não teve desmaio em seguida. Ou seja, 13 trabalhadores já apresentaram desmaios relacionados as atividades de cultivo. A instituição Oswaldo Cruz (FIOCRUZ) alerta em seu manual de biossegurança de 2018 que podemos suspeitar de envenenamento ou intoxicação em qualquer pessoa que apresente após contato com agentes químicos, entre outros aspectos, náuseas, vômitos, diarreias e desconforto estomacal.

Também corroborando com este estudo Itho (2002), relatou sobre a ação dos piretróides sobre a saúde humana em casos de intoxicação, entre eles se destacaram: tontura, cefaléia, distúrbios alérgicos, incoordenação motora, paralisia e distúrbios do equilíbrio, entre outros. Para Hoshino et al. (2008), dentre 
os sintomas que são mais evidentes durante as intoxicações a tontura tem lugar de destaque.

Organização Pan-Americana da Saúde; 2018 categoriza agrotóxicos, amianto, químicas domésticas e ocupacionais, poluição atmosférica ambiental e doméstica, tabagismo passivo, chumbo e arsênico como prejudiciais a saúde humana e impulsiona diversos dados alarmantes quanto a influência destas substâncias no decorrer da vida do trabalhador, e ainda ressalta que as crianças são particularmente vulneráveis aos efeitos agudos e crônicos das substâncias químicas, incluindo intoxicações agudas, exposição à poluição do ar e exposição pré-natal a substâncias químicas. Pessoas idosas são mais vulneráveis aos efeitos crônicos da poluição do ar e à exposição a vários carcinógenos. Neste estudo adotou-se a faixa etária de 18 a 59 anos, mas vale destacar que a presença de crianças e idosos nos ambientes rurais foi sempre observado e principalmente no GF as crianças estavam em piores condições de trabalho.

Outro fato que merece conhecimento e discussão é o caso do sujeito GF15, trabalhador no setor de fumicultura há mais de 20 anos, 44 anos de idade que iniciou o processo de coleta de dados deste trabalho, mas veio a óbito durante o processo. Causa morte foi câncer dos tecidos formadores de sangue, leucemia. No estudo de Miranda et al.,2015, houve o objetivo de revisar as evidências dos efeitos dos agrotóxicos na carcinogênese e sua conclusão foi que a maioria dos estudos apontam associação entre a carcinogênese e a exposição a agrotóxicos, seguido do consumo de alimentos com agrotóxicos, indicando que a população mais vulnerável a esses agentes químicos são os agricultores e suas famílias, pois estão em contato direto. Também corrobora com estes dados o estudo de Bozza e Lopes., 2015, que associaram a exposição a agentes químicos com a presença de leucopenia em frentistas de postos de combustíveis.

A Organização Pan-Americana da Saúde; 2018 estima ainda que os carcinógenos ocupacionais causem entre $2 \%$ e $8 \%$ de todos os cânceres. $4 \mathrm{Na}$ população em geral, estima-se que $14 \%$ dos cânceres de pulmão sejam atribuíveis à poluição do ar ambiental, 17\% à poluição do ar doméstico, 2\% ao tabagismo passivo e $7 \%$ aos carcinógenos ocupacionais. 
Apesar de bastante similares as queixas de GF superam as queixas dos outros grupos, o que pode estar vinculado ao fato de este grupo apresentar contato com mais agrotóxicos e também com os mais tóxicos.

Uma vez que os três grupos estejam submetidos a NPS semelhantes, o que poderá interferir de maneira significante aos achados auditivos é a exposição a outros agentes otoagressores, no caso os agrotóxicos. Em relação ao impacto que os agrotóxicos promovem sobre a saúde humana, Itho (2002) destacou a ação de dois ototóxicos: os organofosforados e carbamatos. Esses inseticidas têm ação de inibição da acetilcolinesterase, e da enzima esterase. A função da acetilcolinesterase é a degradação do neurotransmissor, acetilcolina, com sua inibição ocorrem o acúmulo dessa substância nos receptores nicotínicos, muscarínicos e no Sistema Nervoso Central (SNC). Sendo que com a ação dos oraganofosforados a inibição é irreversível, caso contrário ao caso do carbamatos é reversível, pois permite a recuperação da colinesterase mais ligeiramente.

Conforme previsto nas normas regulamentadoras a audiometria foi um dos procedimentos utilizados neste estudo. Identificou 1 sujeito (A7) do GA com perda auditiva sensorioneural bilateral de grau leve e 8 sujeitos $(A 1, A 4, A 6, A 8, A 10$, A11, A12 e A13) com média dos limiares dentro dos padrões de normalidade, mas em quadro de desencadeamento de perda auditiva ocupacional. Em GF houve 2 sujeitos que apresentaram perda auditiva Sensorioneural bilateral sendo F1 de grau moderado e F13 de grau leve. F2, F3, F5, F9, F11 e F12 apresentaram também limiares característicos de desencadeamento. GA e GF não diferem quanto ao nível de ruído entre eles, ambos atingiram seu pico de NPS em $88 \mathrm{~dB}$. Já quando relacionamos o uso de agrotóxicos, GF apresenta maior quantidade de insumos utilizados e também o maior índice de toxicologia.

Analisados separadamente, os sujeitos que apresentam perda de audição não são os mais velhos do grupo, o que extingue lesão associada a idade. F1 e A7 são os trabalhadores que estão neste ramo a mais tempo e, sendo assim, com maior período de exposição. Corrobora com Sena et al.,2019, que encontrou as piores médias dos limiares de audibilidade em AAF foram encontradas nos trabalhadores expostos a agrotóxicos, independentemente da faixa etária, quando comparadas com aqueles sem exposição a esses agentes. 
Quanto aos demais participantes, os dados corroboram com Morata e Little (2002) que diz que a perda auditiva ocasionada por ototóxicos, se apresenta, em geral, como perda do tipo sensório-neural bilateral simétrica, de caráter irreversível seletiva em altas frequências ( $3 \mathrm{kHz}$ a $6 \mathrm{kHz}$ ) de configuração em entalhe por lesão principalmente em células ciliadas da cóclea. Sena et al., 2013, relacionou uso de agrotóxico e sua classe toxicológica com a classificação de perda auditiva apresentada em seu grupo de estudo. Essa mesma relação pode ser feita no presente estudo. Mesmo estes sujeitos que não apresentaram perda auditiva merecem atenção, conforme Agrawal et al., (2008) muitas vezes a intoxicação ocupacional e ambiental por agrotóxicos é lenta e silenciosa, e as populações podem não sentir dificuldades auditivas que possam ser demonstradas em um audiograma, mas no seu cotidiano perdem a qualidade sonora de uma boa compreensão de fala, o que pode se refletir na dificuldade escolar e mesmo na comunicação com o meio social. Sena et al., 2019, investigou condições auditivas 87 trabalhadores rurais com e sem exposição a agrotóxicos. Assim como no presente estudo encontrou média de limiares normais com entalhe nas frequências de 3,4 e $6 \mathrm{kHz}$ e recuperação em $8 \mathrm{kHz}$. No estudo de Sena et al., 2019, foi constatado ainda que o desempenho das altas frequências pode ser um alarme para detecções precoces de perdas auditivas nestes trabalhadores. Neste estudo também foi observado que os limiares em $12,5 \mathrm{kHz}$, em todos os casos, estiveram abaixo dos demais. Lopes et al., 2012, acredita que a Audiometria de Altas Frequências (AAF) seja considerada 0 instrumento mais eficiente na detecção precoce da perda auditiva até $20 \mathrm{kHz}$, ocasionada por agentes otoagressores, em virtude da caracterização fisiopatológica de tais lesões. A investigação das frequências altas é fundamental para detectar precocemente alterações auditivas principalmente de trabalhadores que ficam expostos a elevados níveis de pressão sonora em seu ambiente de trabalho. Possibilita a identificação das alterações auditivas decorrentes do fator idade, indivíduos expostos a ototóxicos ou zumbido, uma vez que identifica a lesão antes mesmo da queixa ou de alterações identificadas na ATL. (LOPES e BOZZA, 2015). Pensando na evolução dos achados audiológicos está mais alterada a frequência que iniciou o processo de alteração antes das demais. Desta forma incluir a pesquisa de limiares de alta frequências nas avaliações de rotina pode garantir uma detecção precoce de prejuízo auditivo. 
Cada vez mais se faz necessário o acompanhamento das condições auditivas dos trabalhadores mesmo se, nacionalmente, não exista uma obrigatoriedade na legislação trabalhista para a vigilância epidemiológica, por meio da audiometria e/ou testes complementares. Como alternativa de teste complementar, o estudo das Emissões Otoacústicas Evocadas (EOAE) poderia contribuir com o monitoramento audiológico ou identificação precoce de perda auditiva, sobretudo na presença de agentes químicos como são os agrotóxicos. (FLUENTE A, MCPHERSON B,2006; MORATA TC, LACERDA A. 2013). Alcarás PAS et al., 2013, realizou um estudo comparando resultados de EOAE entre um grupo controle e outro grupo exposto a ruído e agrotóxicos. Ao final, o resultado apontou pior funcionalidade de células ciliadas externas no grupo exposto e concluíram ainda que este pode ser um teste a ser incluído na bateria de exame para detecção precoce de alterações auditivas.

Este estudo realizou EOA transientes e observou pior funcionalidade de CCEs em GF seguido por GA. GE se apresentou sem alterações. As frequências mais altas foram as mais prejudicadas, sendo em $4 \mathrm{kHz}$, de GF, o pior desempenho. Coelho et al., 2010 já relacionavam o uso das EOA como eficazes para diagnóstico da PAIR, confirmaram que tanto as emissões otoacústicas transientes (EOAT) quanto às emissões otoacústicas por produto de distorção (EOAPD) são úteis no diagnóstico precoce da PAIR sendo que as EOAT se revelam mais sensíveis às mudanças temporárias de limiar que as EOAPD e as EOAPD se destacam mais eficazes no diagnóstico precoce da PAIR em indivíduos com audição aparentemente normal por captar respostas nas frequências mais agudas que são primeiramente atingidas na PAIR. Pensando que as perdas auditivas com nexo causal nos agentes químicos seguem as mesmas características da PAIR é importante que se considere as emissões otoacústicas como instrumento perspicaz para diagnóstico precoce.

Kós et al., 2013, já manifestava interesse com os efeitos dos agrotóxicos na via auditiva pensando também a nível central e realizou um estudo com o objetivo de avaliar por meio de uma revisão sistemática se a exposição ao agrotóxico causa alterações auditivas no sistema auditivo periférico/central. A revisão foi concluída com 16 trabalhos sendo que 8 avaliaram as vias auditivas utilizando a audiometria tonal; 3 avaliaram com potenciais evocados; 3 avaliaram 
disfunção cognitiva/processamento auditivo; e 2 utilizaram somente questionário para verificar a capacidade auditiva. Daqueles que avaliaram a disfunção de processamento estavam:

- Bosma et al., (2000), cujos achados do estudo sugeriram que o risco de desenvolver alteração do processamento auditivo central leve é aproximadamente cinco vezes maior no grupo exposto a pesticidas do que no grupo não exposto, esse tipo de alteração irá afetar a comunicação do indivíduo, principalmente em ambientes com ruído;

- Teixeira et al., (2002), concluiu que a exposição a piretroides e organofosforado afeta as funções auditivas centrais, dificultando a compreensão das palavras, principalmente na discriminação, situações com ruído;

- $\quad$ Lizardi et al., (2008), que realizou seu estudo com crianças moradoras de uma comunidade rural, e encontrou concentrações elevadas de metabólitos de organofosforado foram associadas significantemente com um desempenho mais pobre nos testes de processamento auditivo central, que podem prejudicar o desempenho escolar.

Os únicos estudos realizados lançando mão do uso do teste P300 foram de Dassanayake et al., que em 2008 realizou uma pesquisa envolvendo fazendeiros expostos a organofosforados. Este grupo apresentou mais alterações no teste de potencial evocado de longa latência, apresentando erros na contagem, e a latência dos potenciais de média e longa latências (P300 e N2) apresentaram diferença estatística significativa entre os dois grupos. Em 2009, Dassanayake et al., pesquisou outros trabalhadores expostos ao mesmo composto e foi encontrado aumento da latência P300 nos indivíduos intoxicados por organofosforado em relação ao grupo controle. Estes resultados podem sugerir alteração do sistema auditivo central. Corroborando com os achados supracitados este estudo avaliou a função central/cognitiva com o teste P300 e tanto GA quanto GF apresentaram diferenças quando comparados a GE. O aumento da latência do potencial p300 esteve presente em 4 participantes de GA e 4 de GF, o que difere os grupos é a presença do participante $\mathrm{F} 13$ que não conseguiu concluir a contagem de estímulos raros alegando não notar a diferença entre eles. É passível de discussão ainda que todos aqueles que apresentaram latência aumentada necessitaram de reteste 
por apresentarem dificuldade em compreender as instruções e/ou diferenciar os estímulos apresentados.

Com isso, ainda que este teste apresente resultados importantes para conhecimento do efeito da exposição aos organofosforados na via auditiva central não se pode dizer que é um teste candidato a detecção precoce das perdas auditivas ocupacionais pois a realização dele é muito interligado ao nível de instrução e de compreensão do trabalhador. Além disso, o tempo de execução desta investigação é muito maior quando comparada aos outros procedimentos.

Os resultados evidenciaram que o GE apresentou maior exposição em relação as intensidades sonoras; o que pode evidencia que apenas a exposição à intensidades sonoras elevadas leva um tempo maior para influenciar os resultados dos limiares auditivos, quando comparados à exposição aos agrotóxicos.

\section{CONSIDERAÇÕES FINAIS}

Diante da literatura compilada, dos testes realizados, resultados obtidos e experiência durante a coleta de dados deste estudo observou-se que a alteração auditiva de trabalhadores expostos a agrotóxicos, sendo fumicultores ou não, apresentou-se com configuração descendente, ou seja, plana entre as frequências de 250 a $2 \mathrm{KHz}$, mais prejudicadas entre $3 \mathrm{KHz}$ a $6 \mathrm{KHz}$ e recuperação em $8 \mathrm{HKz}$, no entanto, nas altas as frequências, a de $12.5 \mathrm{KHz}$ esteve mais prejudicada que as convencionais. A alta frequência mais alterada quando comparada com as demais, corroborando com Lopes, AC (2012). São necessários novos estudos em trabalhados expostos apenas à agrotóxicos para investigar se este comportamento das altas frequências se mantem também para agrotóxicos, uma vez que as frequências mais altas se mantiveram sempre como as mais prejudicadas.

Considerando a bateria de testes adotadas, este estudo sugere que para a avaliação da função auditiva, deva-se incluir as altas frequências, assim como um teste para a avaliação das vias auditivas centrais, incluindo as altas frequências seja o teste mais viável para detecção precoce de alterações auditivas relacionadas ao trabalho. Sugere-se ainda que avaliações em nível central sejam adotadas como medida para o diagnóstico precoce das alterações auditivas. 0 P300, se mostrou eficaz em detectar transtornos do processamento auditivo 
central, apesar de ter sido necessário retestes em GA e GF em função da dificuldade de compreensão dos participantes destes grupos. 


\section{CONCLUSÕES}

Este trabalho concluiu que as condições laborais dos trabalhadores de GA e GF eram precárias, sem instruções quanto ao uso de equipamentos de proteção e manuseio de agrotóxicos. GF relatou maior uso de insumos agrícolas com alta carga toxicológica comparado a GA, ainda que este último também faça uso destes produtos. O nível de ruído não foi alarmante em nenhum dos grupos testados. Quanto aos achados audiológicos, tanto GA quanto GF apresentam traçados compatíveis com desencadeamento de lesões ocupacionais em todos os trabalhadores, no entanto o grupo de fumicultores supera GA na presença de perdas auditivas já instaladas, o que pode sugerir que o tipo do cultivo tenha influência na via auditiva. Estes achados apontam para uma necessidade urgente de maior atenção ao setor de saúde ocupacional agrícola afim de que estes trabalhadores tenham mais acesso às informações relacionadas ao agrotóxico e á necessidade de uso de equipamentos de proteção. Apontam também que a audiometria de altas frequências, assim como um teste para a avaliação do processamento auditivo central deva ser considerado um instrumento de detecção precoce a alterações auditivas nesta população, e que apesar do P300 ter apresentado algumas restrições ele se mostrou eficaz na avaliação da função auditiva central. 


\section{REFERÊNCIAS}

Agrawal Y, Platz EA, Niparko JK. Prevalence of hearing loss and differences by demographic characteristics among US adults. Arch Intern Med 2008; 168:152230 .

ALCARÁS PAS, LARCERDA ABM, MARQUES JM (2013). Estudo das Emissões Otoacústicas Evocadas e efeito de supressão em trabalhadores expostos a agrotóxicos e ruído. CoDAS 2013;25(6):527-33.

ARAÚJO, S.A. Perda auditiva induzida pelo ruído em trabalhadores de metalúrgica. $2002 . \quad$ Disponível em $<$ http://www.scielo.br/scielo.php?script=sci arttext\&pid=S003472992002000100008>.

AZEVEDO, A, 2004. EFEITO DE PRODUTOS QUímicos E RUÍDO NA GÊNESE DE PERDA AUDITIVA OCUPACIONAL. Tese de Mestrado. Fundação Oswaldo Cruz Escola Nacional de Saúde Pública Centro de Estudos da Saúde do Trabalhador e Ecologia Humana. Disponível em $<$ http://teses.icict.fiocruz.br/pdf/azevedoapmm.pdf>

BAZILIO, M. M. M. Avaliação do processamento auditivo temporal (ordenação solução temporal) em trabalhadores rurais expostos a agrotóxicos em Campos, Estado do Rio de Janeiro. 2010. Dissertação (Mestrado em Saúde Coletiva) - Instituto deEstudos em Saúde Coletiva, Universidade Federal do Rio de Janeiro, 2010.

BERTONCELLO, L. EFEITOS DA EXPOSIÇÃO OCUPACIONAL A SOLVENTES ORGÂNICOS, NO SISTEMA AUDITIVO. 1999. PORTO ALEGRE.

Disponível

em<http://www.cefac.br/library/teses/0a5977636e419be3ba93e8ee8400ee72.p

df

Bosna H, van Boxtel MP, Ponds RW, Houx PJ, Jolles J. Pesticide exposure and risk of mild cognitive dysfunction. Lancet 2000; 356:912-3.

BOZZA. A; LOPES. A. Efeito sinérgico da exposição do ruído e agentes químicos no sistema auditivo de trabalhadores de um posto de abastecimento de combustíveis. 2016. Disponível em $<$ http://www.rpso.pt/efeito-sinergico-da-exposicao-do-ruido-e-agentes-quimicosno-sistema-auditivo-de-trabalhadores-de-um-posto-de-abastecimento-decombustiveis/>.

BRASIL. Decreto de lei no 5.452, 13 de maio de 1943. Aprova a consolidação das leis do trabalho. Disponível em <http://www.soleis.com.br/ebooks/0TRABALHISTA.htm>. Aceso em 28 de maio de 2016.

BRASIL. Ministério do Trabalho e Emprego. NR 07 - Programa de. Controle Médico de Saúde Ocupacional - PCMSO. Brasília: Ministério do Trabalho e 
Emprego,

1996.

Disponível

em:<https://www.pncq.org.br/uploads/2016/NR_MTE/NR\%207\%20-

\%20PCMSO.pdf>. Acesso em 20 de outubro de 2016.

Buaski JP, Magni C, Fujinaga CI, Gorski LP, De Conto J (2018). Exposição de mães fumicultoras aos agrotóxicos e os efeitos para a saúde auditiva de lactentes Rev. CEFAC vol.20 no.4 São Paulo July/Aug. 2018

Camarinha CR, Frota SMMC, Pacheco-Ferreira H, Lima MAMT (2011). Processamento auditivo e exposição a agrotóxico. J Soc Bras Fonoaudiol. $2011 ; 23(2): 102-6$

CAMARINHA, C.R; FROTA, S.M.M.C; FERREIRA,H.P; LIMA, M.A.M.T. Avaliação do processamento auditivo temporal em trabalhadores rurais expostos a agrotóxicos organofosforados. 2011. Disponível em $<$ http://www.scielo.br/scielo.php?script=sci arttext\&pid=S217964912011000 $\underline{200004}$ >.Acesso em 08 de agosto de 2016.

CARNEIRO, F.F, AUGUSTO, L. G. C. RIGOTTO, R.M, FRIEDRICH, KAREN, BÚRIGO, A.C. Dossiê ABRASCO - Um alerta sobre os impactos dos agrotóxicos na saúde. ABRASCO, 2015. Rio de Janeiro / São Paulo. Disponível em <http://www.abrasco.org.br/dossieagrotoxicos/wpcontent/uploads/2013/10/DossieAbrasco 2015 web.pdf>

COELHO MSB, FERRAZ JRS, ALMEIDA EOC, ALMEIDA FILHO N (2010). As emissões otoacústicas no diagnóstico diferencial das perdas auditivas induzidas por ruído. Rev. CEFAC, São Paulo 2010.

Coelho MSB, Ferraz JRS, Almeida EOC, Almeida Filho. 2010. EOA no diagnóstico diferencial da PAIR. Rev. CEFAC, São Paulo

Denise Maria Vaz Romano França, Adriana Bender Moreira Lacerda, Diolen Lobato, Angela Ribas, Karin Ziliotto Dias, Tony Leroux \& Adrian Fuente (2017) Adverse effects of pesticides on central auditory functions in tobacco growers, International Journal of Audiology, 56:4, 233-241

Fluente A, McPherson B. Organic solvents and hearing loss: the challenge for audiology. Int J Audiol. 2006;45(7):367-81.

FOLTZ, L.; SOARES, C. D.; REICHEMBAC, M. A. K. Perfil audiológico de pilotos agrícolas. Arq. Int. Otorrinolaringol., São Paulo, v. 14, n. 3, p. 322-330, jul./agost./set.2010.Disponível em $<$ http://www.scielo.br/scielo.php?script=sci arttext\&pid=S180948722010000 300009>.

FRANÇA, D.M.V.R. EFEITOS DO USO DOS AGROTÓXICOS NO SISTEMA AUDITIVO CENTRAL DOS FUMICULTORES DA REGIÃO CENTRO-SUL 
DO PARANÁ. 2013. Tese de Doutorado. Disponível em $<$ http://tede.utp.br:8080/jspui/handle/tede/114>.

GARCIA, E.G. Segurança e saúde no trabalho rural com agrotóxico: contribuição para uma abordagem mais abrangente. 1996. $211 \mathrm{f}$. Dissertação (Mestrado em Saúde Pública) - Universidade de São Paulo, São Paulo, $1996 . \quad$ Disponível em $<$ www.teses.usp.br/teses/disponiveis/6/6134/.../dissert agrotox Eduardo G arcia.pdf.

Gosling.M; Araújo.GCD. 2008. Saúde física do trabalhador rural submetido a ruídos e à carga térmica: um estudo em operadores de tratores. O MundO da Saúde São Paulo: 2008: jul/set 32(3):275-286

Grandjean P, Landrigan PJ. Neurobehavioural effects of developmental toxicity. The Lancet Neurology. 2014;13(3):330-8

HOSHINO, A. C. H; FERREIRA, H.P; TAGUCHI, C.K; TOMITA, S; MIRANDA, M.F.Estudo da ototoxicidade em trabalhadores expostos a organofosforados. Rev. Bras. Otorrinolaringol. vol.74 no. 6. São Paulo Nov./Dec. 2008. Disponível em: <http://dx.doi.org/10.1590/S0034-72992008000600015>.

HOSHINO, A. C. H; FERREIRA, H.P; TAGUCHI, C.K; TOMITA, S; MIRANDA, M.F.Estudo da ototoxicidade em trabalhadores expostos a organofosforados.

Rev. Bras. Otorrinolaringol. vol.74 no. 6. São Paulo Nov./Dec. 2008. Disponível em: <http://dx.doi.org/10.1590/S0034-72992008000600015>.

http://www.fiocruz.br/biosseguranca/Bis/virtual\%20tour/hipertextos/up2/intoxicacoe

s envenenamentos.htm

https://cetesb.sp.gov.br/emergencias-quimicas/aspectosgerais/toxicologia/principais-efeitos-toxicos/

https://sinitox.icict.fiocruz.br/sites/sinitox.icict.fiocruz.br/files//Brasil1.pdf

https://www.unifal-mg.edu.br/riscosambientais/riscosquimicos

HYPPOLITO, M.A; OLIVEIRA, J.A. Ototoxicidade, otoproteção e autodefesa das células ciliadas da cóclea. Revista Médica, v. 38, n. 3/4, jul.-dez. 2005. Disponível em:<http://revista.fmrp.usp.br/2005/vol38n3e4/8_ototoxicidade.pdf>.

IARC. World Cancer Report 2014. Lyon: International Agency for Research on Cancer, Organização Mundial da Saúde; 2014

ITHO, S de F. Curso de Toxicologia: intoxicação por agrotóxicos. (Módulo XII) Rio de Janeiro: UFRJ. Nutes, 2002. Disponível em: $<$ http://ltc.nutes.ufrj.br/toxicologia/mXII.orga.htm>

JERGER, S e JERGER, J. Alterações auditivas. Um manual para avaliação clínica. São Paulo: Atheneu, 1998. 
JUDAI, M.A, ANTUNES, P. A. OTOTOXICIDADE EM TRABALHADORES POR EXPOSIÇÃO a AGROTÓXICOS. 2013. Disponível em $<$ http://amigosdanatureza.org.br/publicacoes/index.php/forum ambiental/arti cle/view/670/694>.

KÖRBES, D. TOXICIDADE DE AGROTÓXICOORGANOFOSFORADO NO SISTEMA AUDITIVOPERIFÉRICO DE COBAIAS: ESTUDO ANATÔMICO EFUNCIONAL. 2009. Tese de mestrado. Disponível em $<$ http://livros01. livrosgratis.com.br/cp109853.pdf >. Acesso em 20 de outubro de 2016

Kós Ml et al., 2013., EFEITOS DA EXPOSIÇÃO A AGROTÓXICOS SOBRE O SISTEMA AUDITIVO Cad. Saúde Pública, Rio de Janeiro, 29(8):1491-1506, ago, 2013

KOS, I.K, HOSHINO, C. A, ASMUS, C.I.F, MENDONÇA, RAPHAEL, MEYER ARMANDO. Efeitos da exposição a agrotóxicos sobre o sistema auditivo periférico e central: uma revisão sistemática. 2013. Disponível em $<$ http://www.scielo.br/pdf/csp/v29n8/v29n8a03.pdf $>$. Acesso em 04 de janeiro de 2016.

KÓS, M.I, MIRANDA,M.F, GUIMARÃES, R.M, MEYER, A. AVALIAÇÃo DO SISTEMA AUDITIVO EM AGRICULTORES EXPOSTOS À AGROTÓXICOS. $2014 . \quad$ Disponível em <http://www.scielo.br/pdf/rcefac/v16n3/1982-0216-rcefac-16-3-0941.pdf>.

LACERDA, A.B.M.; MORATA, T.C.M. O risco de perda auditiva decorrente da exposição ao ruído associada a agentes químicos. In: MORATA, T.C.M; ZUCK, F. (Orgs). Saúde auditiva: avaliação dos riscos e prevenção. São Paulo: Plexus, 2010.p. 99-117.

Lizardi PS, O'Rourke MK, Morris RJ. The effects of organophosphate pesticide exposure on Hispanic children's cognitive and behavioral functioning. J Pediatr Psychol 2008; 33:1-11.

Lopes AC, Melo AD, Santos CC. A study of the high-frequency hearing thresholds of dentistry professionalsInt Arch Otorhinolaryngol 2012; 16(2):226-231

LOPES, Andréa Cintra; GONÇALVES, Cláudia Giglio de Oliveira; ANDRADE, Wagner Teobaldo Lopes de. Fonoaudiologia e saúde auditiva do trabalhador. [S.I: s.n.], 2019.

MANJABOSCO, C. A. W. MORATA, T.C, MARQUES, J.M. Perfil audiométrico de trabalhadores agrícolas. Arq. Int. Otorrinolaringol., v. 8, n. 4, p. 285-295, out./dez.2004.

Disponível

em

$<$ http://arquivosdeorl.org.br/conteudo/acervo port print.asp?id=293> 
MELLO, ANGELA. Alerta ao Ruído Ocupacional. 1999. Disponível em $<$ http://www.cefac.br/library/teses/be957ddf4a068be53e950088fe00d0b3.pd $\mathrm{f}>$.

MINISTÉRIO DA SAÚDE. Textos de epidemiologia para vigilância ambiental em saúde. Brasília (DF): Fundação Nacional de Saúde; 2002. Acesso em 08 de agosto de 2016.2 Disponível em $<$ http://bvsms.saude.gov.br/bvs/publicacoes/funasa/textos vig ambiental.pd $\mathrm{f}>$.

MINISTÉRIO DA SAÚDE/ MANUAL DE VIGILÂNCIADA SAÚDE DE POPULAÇÕES EXPOSTAS A AGROTOXICOS. Brasília, 1997. OPAS/OMS. Disponível em <http://bvsms.saude.gov.br/bvs/publicacoes/livro2.pdf>.

Miranda NM et al. 2015. Evidências dos efeitos dos agrotóxicos na carcinogênese.

Morata TC, Lacerda A. Saúde Auditiva. In: Zeigelboim BS, Jurkiewicz AL, organizadores. Multidisciplinaridade na otoneurologia. São Paulo: Roca; 2013. p. 429-44.

Morata TC, Little B. Suggested guidelines for studying the combined effect of occupational exposure to noise and chemicals on hearing. Noise Health 2002; 4(14):73-87.

MOREIRA, J.; JACOB, S.; PERES, F.; LIMA, J.; MEYER, A.; SILVA, J.; SARCINELLI,P.; BATISTA, D.; EGLER, M.; FARIA, M.; ARAÚJO, A.; KUBOTA, A.; SOARES, M.; ALVES, S.; MOURA, C.; CURI, R. Avaliação Integrada do impacto do uso de agrotóxicos sobre a saúde humana em uma comunidade agrícola de Nova Friburgo, RJ.Ciência \& Saúde Coletiva, v. 7, n. 2, p. 299-311, 2002. Disponível em $<$ http://www.scielo.br/pdf/csc/v7n2/10249.pdf $>$.

Não polua o meu futuro! O impacto do ambiente na saúde das crianças. Brasília, DF: Organização Pan-Americana da Saúde; 2018. Licença: CC BY-NC-SA 3.0 IGO.

Norman RE, Ryan A, Grant K, Sitas F, Scott JG. Environmental contributions to childhood cancers. Journal of Enviromental Immunology and Toxicology. 2014;2(2):86-98. 73

O impacto de substâncias químicas sobre a saúde pública: Fatores conhecidos e desconhecidos. Brasília, DF: Organização Pan-Americana da Saúde; 2018. Licença: $\quad$ CC $\quad$ BY-NC-SA $3.0 \quad$ IGO. http://iris.paho.org/xmlui/handle/123456789/49122

OLMI, C.R. PAIR - perda auditiva induzida pelo ruído. 2011. Disponível em $<$ http://www.redentor.inf.br/arquivos/pos/publicacoes/06072012TCC\%20Cris tina\%20Riani\%200Imi\%20-\%20101504.pdf>. 
Organização Mundial da Saúde. 2 OMS (2015). Observatório Global da Saúde (GHO). Veja: http://www.who.int/gho/es/ (acessado em 3 de dezembro de 2015)

Prüss-Ustün A, Wolf J, Corvalán C, Bos R, Neira M (2016). Preventing disease through healthy environments: A global assessment of the environmental burden of disease. Genebra:

RIBEIRO, B.L, MACHADO, A.A, BACK, D.C. Perda auditiva induzida por níveis de pressão sonora elevados na indústria.2009. Disponível em $<$ http://www.cefac.br/library/artigos/4994382af80a4b40a3fdd9dea3e405e9.p $\underline{\mathrm{df}}>$.

ROSÁRIO, Ana Elisabete Fontana de Paula; TOPANOTTI, Jenane; MAGNI, Cristiana; LOPES, Andréa Cintra; CASSOL, Karlla. Conhecimento e ações desenvolvidas pelos agentes comunitários de saúde sobre saúde auditiva: revisão de literatura. Revista Thêma et Scientia, Cascavel, v. 7, n. 2E, p. 195-205, 2017.

SANTOS. NF; et al., 2019. Evidências dos Efeitos Neurotóxicos por Exposição ao Agrotóxico: Uma revisão Integrativa. Atas CIAIQ2019.

Schlindwein VLDC. Dor e sofrimento oculto: a desproteção social dos trabalhadores do fumo. Barbaroi 2010; (32):82-97.

Sena TRR et al.. Saúde auditiva e qualidade de vida em trabalhadores expostos a agrotóxicos. Ciência \& Saúde Coletiva, 18(6):1753-1761, 2013

SENA, T.R.R, VARGAS,M.M, OLIVEIRA,C.C da C. Saúde auditiva e qualidade de vida em trabalhadores expostos a agrotóxicos. 2013. Disponível em $<$ http://www.scielo.br/scielo.php?script=sci arttext\&lng=pt\&nrm=iso\&tlng=pt \&pid=S1413-81232013000600026 > . Acesso em 04 de janeiro de 2016.

Sena. TRR., et al Audição em altas frequências em trabalhadores rurais expostos a agrotóxicos. iênc. saúde coletiva vol.24 no.10 Rio de Janeiro Oct. 2019

SINITOX - Sistema Nacional de Informações Tóxico-Farmacológicas. Ministério da Saúde, Fundação Oswaldo Cruz, 2006. Disponível em:<http://www.fiocruz.br/sinitox_novo/cgi/cgilua.exe/sys/start.htm?tpl=hom e

SOUZA, M. T, BERNARDI, A.P de A, FIORINI, A.C, COSTA, E.A, IBANEZ, R.N, SENA, T. R.R.Perda Auditiva Induzida por Ruído (Pair). 2006. Disponível em $<$ http://bvsms.saude.gov.br/bvs/publicacoes/protocolo perda auditiva.pdf $>$. 
Teixeira CF, Augusto LGS, Morata TC. Occupational exposure to insecticides and their effects on the auditory system. Noise Health 2002; 4:31-9.

TEIXEIRA, C. F.; AUGUSTO, L. G. S.; MORATA, T. C. Saúde auditiva de trabalhadores expostos a ruído e inseticidas. Rev. Saúde Pub., v. 37, n. 4, p. 417-423, mar. 2003. Disponível em $<$ http://www.scielo.br/scielo.php?script=sci arttext\&pid=S003489102003000 $\underline{400005}>$.

Tharaka Lagath Dassanayake, 2017. COGNITIVE TOXICITY: FROM

PESTICIDES TO PHARMACEUTICALS. Sri Lanka Journal of Medicine Vol. 26 No.1, 2017

TRABANCO, Júlio César Gonçalves. Efeitos da exposição a produtos químicos ou ao ruído sobre a audição. 2019. Dissertação (Mestrado em Ciências da Reabilitação) - Faculdade de Medicina, University of São Paulo, São Paulo, 2019. doi:10.11606/D.5.2019.tde-09122019-111716. Acesso em: 2019-1230. 
Apêndice 
Apêndice

\section{Apêndice 1}

\section{ENTREVISTA}

1- Qual é o seu sexo? ( )M ( )F

2- Quantos anos você tem?

3- Há quanto tempo você trabalha nessa profissão?

a-) 0 a 1 ano

b-) 1 a 5 anos

c-) 5 a 10 anos

d-) Mais de 10 anos

4- Quantas horas você trabalha por dia?

5- Onde você faz o horário do almoço?

( ) No trabalho

( ) Próximo ao trabalho

( ) Fora do trabalho

6- Você usa equipamentos de proteção?

( ) $\operatorname{sim}$

( ) não

Quais

Você recebeu instruções para este uso? ( ) sim ( ) não

7- Em uma escala de 0 a 10, como você classifica a região em que trabalha? (0 silenciosa e 10 muito barulhenta )

0

5

10

8- No seu trabalho você tem contato direto com algum produto químico?

( ) $\operatorname{sim}$

( ) não

Qual

9- Em uma escala de 0 a 10, como você classifica sua audição? ( 0 muito ruim e 10 muito boa)

\begin{tabular}{lll}
\hline 0 & 5 & 10
\end{tabular}


Apêndice

\section{Apêndice 2}

\section{QUESTIONÁRIO AGRICULTORES}

OBJETIVO: (para analisar a autopercepção dos trabalhadores diante do risco a exposição aos agrotóxicos)

1 - Nome:

2 - Idade:

3- Sexo: ( ) fem ( ) mas

4- Há quanto tempo trabalha na agricultura?
a- 1 a 5 anos
b- 6 a 10 anos
c- 11 a 15 anos
d- Mais de 15 anos

5- Em época de safra, quantas horas trabalha por dia?
a- 1 a 5 horas
b- 5 a 8horas
c- Mais que 8 horas

6- Qual a cultura que trabalha?

a- ( ) fumo

b- ( ) soja, milho, feijão etc.

C- ( ) outras culturas

7- Faz uso de agrotóxicos (venenos para a lavoura)?
a- $\operatorname{Sim}$
b- Não
Se sim, sabe dizer o nome?

8- Recebeu alguma instrução sobre o uso e as consequências dos produtos agrícola?
a- $\operatorname{Sim}$
b- Não

9- Considera o ambiente de trabalho ruidoso?
a- $\operatorname{Sim}$
b- Não
c- Muito
d- Às vezes

10- Faz uso dos equipamentos de proteção (EPI) como luvas, botas, máscaras e protetores auriculares por exemplo?
a- Sim
b- Não

Se Sim, qual? 
11- Recebeu treinamento para o uso do EPI?
a- Sim
b- Não

12- Quanto tempo por dia fica em contato com os agrotóxicos (venenos para a lavoura)?
a- Menos de 1 hora
b- 1 a 3 horas
c- 4 a 7 horas
d- Mais de 7 horas

13- As lavouras são próximas a residência (casa)?
a- $\operatorname{Sim}$
b- Não

14- Tem conhecimento dos riscos a saúde que o agrotóxico causa?
a- $\operatorname{Sim}$
b- Não
Comentários

15- Já passou mal depois que utilizou agrotóxicos na lavoura?
a- $\operatorname{Sim}$
b- Não

Qual a queixa?

16- Faz uso constante de agrotóxicos?
a- Todos os dias
b- Três vezes por semana
c- Duas vezes por semana
d- Uma vez por semana
e- Uma vez por mês
f- Uso não periódico

17- Relaciona o seu trabalho a sua saúde auditiva?
a- $\operatorname{Sim}$
b- Não

18 - Numa escala de 0 a 10, como você classifica sua audição? (Sendo 0 muito ruim e 10 muito boa)

\begin{tabular}{lll}
\hline 0 & 5 & 10
\end{tabular}


Apêndice 
ANEXO 1

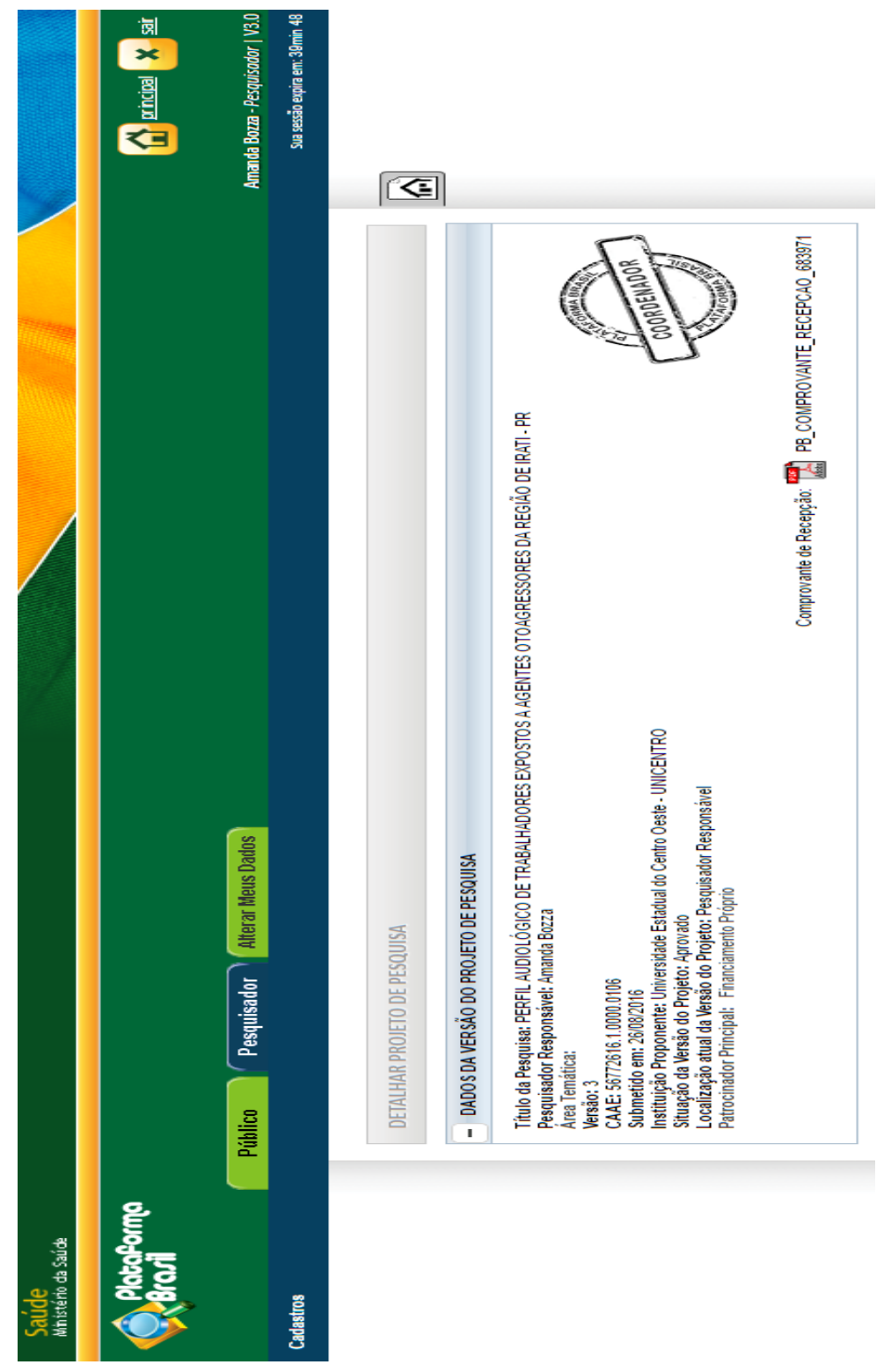




\section{ANEXO 2}

\section{TERMO DE CONSENTIMENTO LIVRE E ESCLARECIDO}

Eu, Amanda Bozza, professora do curso de Fonoaudiologia da Universidade Estadual do CentroOeste, estou convidando você para participar de um estudo intitulado "Caracterização das condições auditivas de trabalhadores agrícolas da região de Irati- PR.", que tem por objetivo investigar as condiç̧oses auditivas de trabalhadores agricolas da região de Irati- PR.

Caso você participe da pesquisa, será necessário fornecer alguns dados pessoais, além de responder perguntas de um questionário sobre a.autopercepção dos trabalhadores diante do risco a exposição aos agrotóxicos

Lembramos que sua participação neste estudo é voluntária, portanto poderá desistir a qualquer momento, mesmo que 0 estudo já tenha sido começado, não trazendo nenhum prejuízo. Seus dados ou qualquer informação pessoal serão utilizadas somente para esta pesquisa, sendo preservados em perfeito sigilo e não irão aparecer nem quando forem apresentados os resultados da pesquisa.

A Prof.'Amanda Bozza,e-mail amandabozza@yahoo.com.br(42) responsável por este estudo, poderão ser contatadas na Universidade Estadual do Centro-Oeste (UNICENTRO), sediada na PR153 KM 07, CEP 84.500-000, no Bairro Riozinho da cidade de Irati, Estado do Paraná, CNPJ/MF № 77902914/0001-74, Fone (42) 3421- 3224 ou nos e-mails e celulares acima, para esclarecer eventuais dúvidas que $0 \mathrm{Sr}(a)$. possa ter. Podemos fornecer as informações necessárias ou esclarecer suas dúvidas, antes, durante e depois do término do estudo.

As despesas necessárias para esta pesquisa não serão de sua responsabilidade, ou seja, você não terá que arcar com nenhuma despesa, todos os gastos serão subsidiados pelo pesquisador, porém também não receberá valor algum em dinheiro para participar do estudo.

Se estiver de acordo e quiser participar do estudo, deve assinar logo abaixo, concordando com os termos, e receberá uma cópia deste documento, que será impresso em duas vias.

$\begin{array}{lccccc}\text { Pelo presente instrumento que atende às exigências legais, } & 0 \\ \text { Sr.(a) } & & \text { portador(a) da cédula } & \text { de }\end{array}$
identidade declara que, após leitura minuciosa do TCLE, teve oportunidade de fazer perguntas, esclarecer dúvidas que foram devidamente explicadas pelos pesquisadores, ciente dos serviços e procedimentos aos quais será submetido e, não restando quaisquer dúvidas a respeito do lido e explicado, firma seu CONSENTIMENTO LIVRE E ESCLARECIDO em participar voluntariamente desta pesquisa.

E, por estar de acordo, assina o presente termo.

Irati, __ de de 2016 